GOVERNANCE AND THE EFFICIENCY

OF ECONOMIC SYSTEMS

GESY

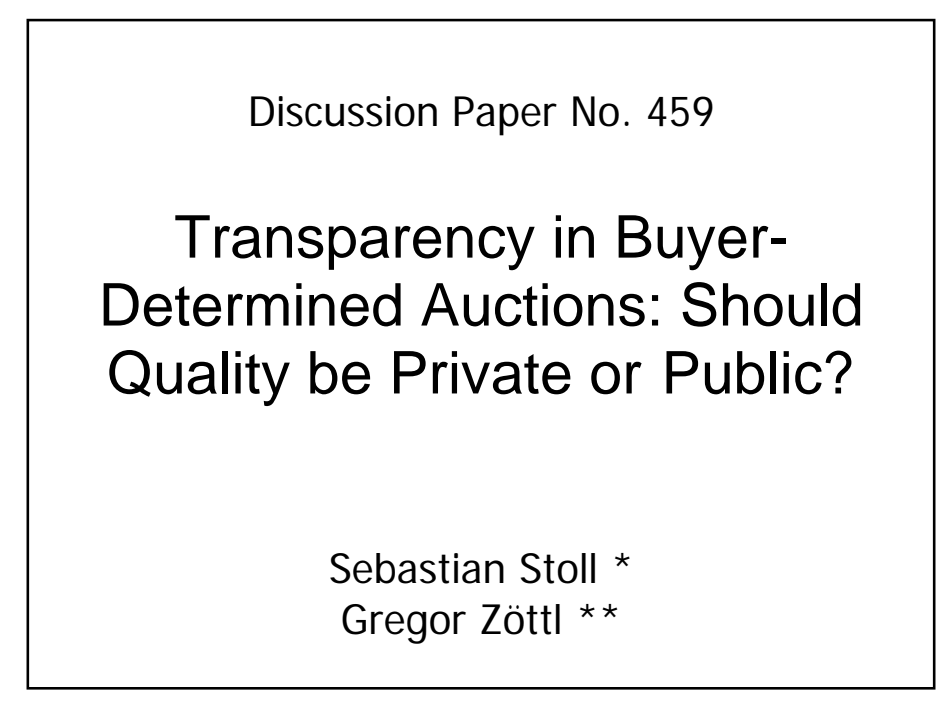

* University of Munich and

Max Planck Institute for Innovation and Competition

** University of Erlangen/Nuremberg

March 2014

Financial support from the Deutsche Forschungsgemeinschaft through SFB/TR 15 is gratefully acknowledged. 


\title{
Transparency in Buyer-Determined Auctions: Should Quality be Private or Public?*
}

\author{
Sebastian Stoll’ Gregor Zöttl ${ }^{\ddagger}$
}

March 27, 2014

\begin{abstract}
We study non-binding procurement auctions where both price and nonprice characteristics of bidders matter for being awarded a contract. The outcome of such auctions critically depends on how information is distributed among bidders during the bidding process. As we show theoretically, whether it is in the buyer's interest to conceal or to disclose non-price information most importantly depends on how important the quality aspects of the good to be procured are to the buyer: The more important the quality aspects are to the buyer, the more interesting concealment becomes. We then empirically study the impact of a change in the information structure using data from a large European online procurement platform for different categories of goods. In a counterfactual analysis we analyze the reduction of non-price information available to the bidders. In the data we find that the choice of information structure indeed matters. Confirming the hypothesis obtained in our theoretical framework, we find that in auction categories where bidders' non-price characteristics are of little importance for the decisions of the buyers, concealment of nonprice information decreases buyers' welfare by up to $6 \%$ due to reduced competitive pressure leading to higher bids. In contrast, for categories where bidders' non-price characteristics strongly influence buyers' decisions concealment of non-price information increases buyers' welfare by up to $15 \%$.
\end{abstract}

Keywords: Procurement, Non-Binding Auctions, Supply Chain Management

\footnotetext{
${ }^{*}$ We thank Veronika Grimm, Dietmar Harhoff, Reiner Opgen-Rhein, Markus Reisinger, Klaus Schmidt, Monika Schnitzer, Otto Toivanen, Achim Wambach and Christine Zulehner for their helpful comments and suggestions. Sebastian Stoll gratefully acknowledges financial support by the Deutsche Forschungsgemeinschaft (DFG) through GRK 801.

†Sebastian Stoll, University of Munich and Max Planck Institute for Innovation and Competition, Germany. Email: sebastian.stoll@ip.mpg.de.

${ }^{\ddagger}$ Gregor Zöttl, University of Erlangen-Nuremberg, Germany. Email: gregor.zoettl@fau.de.
} 


\section{Introduction}

When procuring a contract, the buyer often is not only interested in the price of an offer but also in other, non-price dimensions such as technical characteristics of the good or time of delivery. A by now quite well studied multidimensional auction format is given by scoring auctions where buyers prior to the bidding process establish a binding scoring rule. Besides such highly structured auctions, recently "non-binding" or "buyer-determined" auctions became increasingly important. In these auctions buyers can freely assign the contract after bidding has taken place. Currently this auction format seems to establish itself as the most prominent one for online marketplaces both for private and commercial contractors. $^{1}$

When designing non-binding procurement auctions, typically no structure is imposed on the buyer's decision process - he is entirely free to choose any of the submitted bids. Important design questions arise, however, with respect to the optimal information structure for the bidding process. That is, bidders can be provided with different levels of information regarding the prices and the non-price characteristics of rival offers. Non-binding procurement auctions can be open-bid or sealed-bid auctions. If a non-binding auction is a sealed bid auction, bidders are usually neither informed about their rivals' prices nor their rivals' non-price characteristics. However, in this article we do not deal with sealed-bid auctions. Instead, we are interested in open non-binding procurement auctions. In open non-binding auctions bidders are informed about their rivals' prices throughout the bidding process. The design question which arises here with regard to the information structure is whether information about their rivals' non-price characteristics is disclosed to or concealed from bidders.

In the present article we shed light on the optimal design of the information structure of open non-binding reverse auctions, using an extensive dataset from a large European online procurement platform. Our analysis focuses on the impact of transparency of the auction

\footnotetext{
${ }^{1}$ See Jap (2002, 2003), Jap and Haruvy (2008), and compare for example the platform FedBid, Inc., where US government agencies have procured more than $\$ 4.1$ billion worth of purchases since 2008 using non-binding auctions.
} 
design with respect to bidders' non-price characteristics. In particular, we are interested in the effect of concealment of non-price information on the auction outcome. Theoretically, we find that the effect of concealment of non-price information depends on how the buyer weighs bidders' non-price characteristics against bidders' prices. We then do a counterfactual analysis to assess the relevance of this finding for applications in the field. If non-price information was concealed from the bidders, we would expect aggregate welfare of the buyers to increase by up to $15 \%$ for auction-categories where non-price characteristics heavily influence buyers' decisions. The reason is that concealment of non-price information makes bidders appear more similar to each other, which increases competitive pressure and leads to lower bids. In contrast, in auction-categories where bidders' non-price characteristics only weakly influence buyers' decisions, in case non-price information were concealed we would expect aggregate welfare of the buyers to decrease by up to $6 \%$.

Our analysis proceeds as follows: First, we establish two formal frameworks which describe two limiting cases of information structures. In the first case, bidders are fully informed about the non-price characteristics of their rivals. In the second case, all non-price information is concealed from the bidders. We show that whether it is beneficial for buyers to reveal non-price information depends on characteristics of the market considered, namely the relationship between the differences in the bidders' costs and that in their qualities. A bidder's quality simply denotes how buyers value that bidder's non-price characteristics. The main intuition here is that when bidders are quite different in terms of how their non-price characteristics are valued by the buyers, then concealment of non-price information makes bidders appear more similar than they actually are, which toughens competition among bidders and in turn increases buyers' welfare.

Our empirical analysis is based on a detailed data set of an online procurement platform, where subscribed buyers post their tenders and can freely choose among the posted bids. For the period of observation all non-price information is publicly available to bidders. As a first step of our empirical analysis, for different auction categories we analyze how 
buyers value bidders' non-price characteristics. We then verify whether bidders indeed are aware of the buyers' preferences over their own and their rivals' non-price characteristics. Our theoretical frameworks imply that in this case, contrary to the case where non-price information is concealed from the bidders, the bids should directly take into account the non-price characteristics of rivals' bids. By exploiting the fact that a subset of bidders is observed to participate in several auctions, we are able to identify the bidders' reactions to changing compositions of their rivals' non-price characteristics. We find that bidders submit significantly lower bids when confronted with rivals whose non-price characteristics are very valuable for the buyer.

After showing that bidders' observed behavior is indeed in line with our model for the case of disclosed non-price information, we conduct a counterfactual analysis to assess the economic significance of concealment of quality information for applications in the field. Using our model for the case of disclosed non-price information, we first derive estimates of the bidders' costs. We find that bidders' markups, which we compute using our cost estimates, are of expected size and in line with economic intuition. We then use these cost estimates together with our model for the case of concealed non-price information to compute bidders' counterfactual prices. With these we finally calculate the change in the aggregate welfare of the buyers in case non-price information is concealed from the bidders. We do this for several job-categories which differ with respect to the relevance of non-price characteristics for buyers' decisions. We find that our theoretical predictions are of direct practical relevance for the dataset considered: For job-categories where non-price characteristics are of rather low importance (in our sample "moving" and "painting"), our counterfactual results show that in case non-price information were concealed bidders' prices would increase and the number of closed deals would decrease. In effect, buyers' aggregate welfare would decrease by up to $6 \%$. With respect to turnover created in all auctions, the decrease in the number of closed deals seems to outweigh the increase in bidders' prices: Turnover would decrease by up to $2 \%$. For job-categories where non-price characteristics are highly relevant (in our 
sample car repairs), prices would not significantly change but the number of closed deals would increase. This would increase both buyers' aggregate welfare (by up to 15\%) and turnover (by up to $13 \%$ ).

Our work adds to a relatively new strand of literature which analyzes non-binding auctions. From a more general perspective this clearly contributes to the literature which analyzes efficient ways to procure contracts when the buyer's valuation of an offer depends on additional dimensions besides price. Scoring auctions (where binding scoring rules take price and non-price characteristics into account) have already received significant attention in the literature are well understood by now. Asker and Cantillon $(2008,2010)$ show that for the case when suppliers have multi-dimensional private information, this procurement mechanism dominates others like sequential bargaining and price-only auctions. Different scoring auction designs are compared in Che (1993), Branco (1997), Chen-Ritzo et al. (2005) and Kostamis et al. (2009). Empirical analysis of scoring auctions can be found in Athey and Levin (2001) and Lewis and Bajari (2011), the first using data from US timber auctions and the second data from US highway procurement auctions. Practical implementability of scoring auctions through iterative process is analyzed for example in Bichler and Kalagnanam (2005) or Parkes and Kalagnanam (2005). Finally, in a theoretical contribution Che (1993) compares scoring auctions with non-binding auctions. He shows that when bidders bid on all dimensions of their offers, from the buyer's perspective scoring auctions dominate nonbinding auctions.

Several recent articles compare the performance of non-binding auctions to regular price only auctions. Engelbrecht-Wiggans et al. (2007) is one of the seminal articles in this context. They analyze both analytically and experimentally under which conditions the buyer would want to commit to a price only mechanism which ignores all non-price attributes. As the authors establish, such commitment is only desirable when competitive pressure is important (few bidders) and expected quality of the low-cost bidders is not too low (limited negative 
correlation between cost and quality). ${ }^{2}$ Fugger et al. (2013) find in a recent contribution that when bidders are uncertain about the exact way different criteria enter the final decision of the buyer, there are cases where a non-binding auction enables them to coordinate on high prices. In that case the buyer would prefer binding price-only auctions over non-binding auctions. In a recent experimental study Brosig-Koch and Heinrich (2014) show that buyers prefer buyer-determined auctions over price only-auctions.

Wan and Beil (2012) and Wan et al. (2012) analyze related but slightly different problems. They study auctions where bidders in order to win the auction additionally have to meet certain quality standards. Those articles explore theoretically and experimentally under which conditions it is optimal to provide information with respect to the screening among bidders either prior or after bidding has taken place.

We are especially interested in the effect of different information structures in non-binding auctions. Several theoretical articles analyze the conditions under which it is beneficial for the buyer in non-binding auctions to inform bidders about their qualities. Gal-Or et al. (2007) analyze sealed bid auctions and procurement by sequential search. As they show, for the latter case the buyer is typically better off when he discloses quality information to the bidders. Extensions such as the inclusion of risk averse bidders are provided in Doni and Menicucci (2010). Colucci et al. (2011) extend the setting of Gal-Or et al. (2007) by introducing heterogeneity in bidders' costs. They demonstrate that for the case of large cost differences and a comparatively small weighting of quality aspects it is in the best interest of the buyer to conceal quality information. In the opposite case, he is better off disclosing information about the bidders' qualities. ${ }^{3}$

\footnotetext{
${ }^{2}$ In principle, also our setting compares a non-binding auction (with informed bidders) with a "priceonly"-regime. In our setting, however, "price-only" refers solely to the information held by the bidders, who know that prices matter, but are uncertain with respect to all other criteria. The buyers always do choose the ex post best offer, taking into account all non-price characteristics (as in Gal-Or et al., 2007; Doni and Menicucci, 2010; Haruvy and Katok, 2013). The fundamental insights obtained in our analysis are thus clearly quite different. As one consequence, for example, the correlation between cost and quality, which is crucial in Engelbrecht-Wiggans et al. (2007), is not of central importance in our setting since foregone quality is not an issue.

${ }^{3}$ For a similar setting Rezende (2009) shows that when the buyer and the suppliers have the possibility to renegotiate, it can be optimal for the buyer to fully reveal the information about the suppliers' qualities.
} 
In a recent article, Haruvy and Katok (2013) are the first ones to shed more light on those issues from an empirical perspective. Based on controlled laboratory experiments, they analyze both open and sealed bid non-binding auctions and assess the impact of information revelation on bids submitted. For the parameter environments chosen in their laboratory experiments they find that in their open auction design due to more aggressive bidding buyers are better off if they keep information about bidders' qualities concealed. Our work differs from their contribution since our analysis is based on field data of indeed conducted auctions. Our analysis, moreover, is conducted for several different services to be procured, and thus allows us to identify under which conditions information revelation indeed is desirable in open non-binding auctions. That is, for the case of car repairs our results are in line with those obtained by Haruvy and Katok (2013), whereas for the case of moving and painting we obtain opposite results.

The article proceeds as follows. Section 2 introduces our theoretical frameworks for the case of disclosed and that of concealed non-price information and derives under what conditions a buyer prefers which information regime. Section 3 introduces our dataset. In section 4, for different auction categories we analyze how buyers value bidders' non-price characteristics, and in section 5 we use a reduced-form model to show that bidders' behavior is indeed in line with our framework for the case of disclosed non-price information. Based on these preparations, in section 6 we perform a counterfactual analysis to assess how strongly buyers' welfare can be expected to change if non-price information gets concealed from the bidders. This is done for several auction categories. Section 7 concludes.

\section{Theoretical Framework}

- Framework. We consider a non-binding and open procurement situation where a buyer wants to procure some contract among $J$ participating firms. Each firm has some $\operatorname{cost} c_{j}$ for providing the service (later on, we will discuss the cases of costs being either 
known or unknown among firms). Bids can be submitted and updated at any point in time $t$ throughout a given period, $t \in[0 ; T]$. That is, firms $j=1, \ldots, J$ observe the current bids of all players and are free to update their bids $b_{j}(t)$ whenever they want to. We denote the vector of final bids $b_{j}(T)$ quoted by each firm once bidding has stopped by $\mathbf{p}=\left(p_{1}, \ldots, p_{J}\right)$. Once price submission has finished the buyer can freely choose to award the contract to some firm $j$ at price $p_{j}$.

For the buyer's decision not only the final price $p_{j}$ quoted by firm $j$ matters but also its non-price characteristics, which we denote by $\mathbf{A}_{j}$, and which we assume to be exogenously given. In analogy to the existing literature on non-binding procurement auctions, we call the value of these non-price characteristics to the buyer a firm's quality $q_{j}$. Given the buyer's preferences regarding these non-price characteristics, which we denote by $\boldsymbol{\alpha}$, we assume that the quality of firm $j$ is a linear function non-price characteristics and preferences, that is $q_{j}=\boldsymbol{\alpha} \mathbf{A}_{j}$.

Throughout our analysis, we assume that the buyer is always fully informed about each firm's non-price characteristics. However, with respect to the information firms receive about other firms' non-price characteristics we differentiate between two cases: In the first case, which we call information case (IC), each firm is informed about each other firm's non-price characteristics and the corresponding preferences of the buyer. That is, in the information case qualities of all firms are common knowledge. In the other case, which we call no information case (NIC), the firms are not informed at all about qualities.

We assume that the buyer can choose among $J$ firms and an outside option. He receives a certain amount of utility $u_{j}$ when he chooses firm $j$. This amount of utility depends on the price $p_{j}$ put forward by this firm and the firm's exogenous non-price characteristics $\mathbf{A}_{j}$. We model the utility a buyer receives from a certain firm as being linearly dependent on the price $p_{j}$, the firm's non-price characteristics $\mathbf{A}_{j}$, and an error term $\epsilon_{j}$. With that, we assume 
the buyer's decision process to be given as

$$
\begin{aligned}
\max _{j \in\{0,1, \ldots, J\}} & u_{j}, \text { where } \\
u_{0} & =t+\epsilon_{0} \\
u_{1} & =-p_{1}+\boldsymbol{\alpha} \mathbf{A}_{1}+\epsilon_{1} \\
& \vdots \\
u_{J} & =-p_{J}+\boldsymbol{\alpha} \mathbf{A}_{J}+\epsilon_{J}
\end{aligned}
$$

$\boldsymbol{\alpha}$ denotes the vector of the buyer's preferences regarding firms' non-price characteristics. $t$ denotes the value of the buyer's outside option. For simplicity and without loss of generality we normalize the price coefficient to -1 . The error terms $\epsilon_{j}$ capture unobserved influences on the buyer's decision which are unrelated to price or non-price characteristics. When making his decision, the realizations of the $\epsilon_{j}$ are known to the buyer, but they always remain concealed from the firms. The buyer is assumed to choose the option which maximizes his utility, that is, the option $k$ for which

$$
u_{k}>u_{j} \quad \forall j \neq k, \quad j, k \in\{1, \ldots, J\}
$$

Information case. We assume that in the information case firms have full information about all firms' non-price characteristics A and the corresponding preferences of the buyer. In a non-binding auction, in contrast to a scoring auction, there is no binding and publicly known scoring rule. That is, firms are not explicitly informed about the way the buyer makes his decision. Instead, we assume that firms collected information about the buyer's decision process (that is, his preferences $\boldsymbol{\alpha}$ regarding their non-price characteristics) by observing 
past auctions. Thus, each firm's model of the buyer's decision process is given as

$$
\begin{aligned}
\max _{j \in\{0,1, \ldots, J\}} & u_{j}, \quad \text { where } \\
u_{0} & =t+\epsilon_{0} \\
u_{1} & =-p_{1}+\boldsymbol{\alpha} \mathbf{A}_{1}+\epsilon_{1} \\
& \vdots \\
u_{J} & =-p_{J}+\boldsymbol{\alpha} \mathbf{A}_{J}+\epsilon_{J} .
\end{aligned}
$$

Note that in contrast to the buyer, who knows the realizations of the $\epsilon_{j}$ when making his decision, from the firms' perspectives the $\epsilon_{j}$ are random. We assume that the unobservables $\epsilon_{j}$ follow some distribution, and that the firms know the distribution of the $\epsilon_{j}$. In consequence, given some bid $p_{j}$ of its own, firm $j$ can derive all winning probabilities $P_{k}(\mathbf{p}, \mathbf{A}), k \in$ $\{0,1, \ldots, J\}$. These winning probabilities are functions of all firms' final price bids $\mathbf{p}=$ $\left(p_{1}, \ldots, p_{J}\right)$ and all firms' non-price characteristics $\mathbf{A}=\left(\mathbf{A}_{1}, \ldots, \mathbf{A}_{J}\right)$. We assume that the winning probability $P_{k}$ of each firm $k$ is $\log$ concave in its final price quote. ${ }^{4}$ Expected profits $\pi_{j}$ of firm $j$ are given by

$$
\pi_{j}=P_{j}(\mathbf{p}, \mathbf{A})\left(p_{j}-c_{j}\right)
$$

We now proceed and determine an equilibrium based on an appropriately chosen equilibrium concept for the dynamic bidding game. For the sake of exposition, we first assume that cost $c_{j}$ for $j=1, \ldots, J$ are known among firms (below we then also discuss the case of unknown cost of rivals). All firms have the same information, we can thus proceed to solving the game by simple backwards induction. Since, furthermore, only final bids are payoff-relevant in our framework, we only need to identify the mutually best responses to the final price bids of all rivals. We denote the final equilibrium outcome of the dynamic

\footnotetext{
${ }^{4}$ Notice that the logit framework referred to from section 6 onwards satisfies this assumption.
} 
bidding game by $\mathbf{p}^{*}$. It is characterized by the following expression:

$$
p_{j}+\frac{P_{j}}{\partial P_{j} / \partial p_{j}}-c_{j}=0, \quad \forall j \in\{1, \ldots, J\}
$$

The winning probabilities $P_{j}$ follow from (2) and depend on all bidders' prices $\mathbf{p}$ and nonprice characteristics A. Existence and uniqueness of $\mathbf{p}^{*}$ as characterized by (3) has already been shown in the literature, compare Caplin and Nalebuff (1991) and Mizuno (2003). ${ }^{5}$

No information case. We assume that in the no information case firms are not informed about qualities at all. ${ }^{6}$ Analogous to the information case we assume that there is no binding and publicly known scoring rule, but that firms instead had to collect information about the buyer's decision process from observing past auctions. With non-price information concealed, in their model of the buyer's decision process firms can only take into account the observable prices. That is, we assume the firms' model of the buyer's decision process to be:

$$
\begin{aligned}
\max _{j \in\{0,1, \ldots, J\}} & u_{j}, \quad \text { where } \\
u_{0} & =\tilde{t}+\tilde{\epsilon}_{0} \\
u_{1} & =-p_{1}+\tilde{\epsilon}_{1} \\
& \vdots \\
u_{J} & =-p_{J}+\tilde{\epsilon}_{J} .
\end{aligned}
$$

Note that, in contrast to the buyer, firms do not know about the realizations of the $\tilde{\epsilon}_{j}$. Given final price bids $\mathbf{p}$, firm $j$ can derive winning probabilities $\tilde{P}_{k}, k \in\{0,1, \ldots, J\}$. These

\footnotetext{
${ }^{5}$ For a complete statement of the equilibrium strategy profile we also need to specify bidding behavior for all instances prior to the end of the auction. There are several possibilities to do so, a natural choice is to choose $b_{j}^{*}(t)=p_{j}^{*}$ for all $j=1, \ldots, J$ and for all $t<T$. Notice that multiple subgame-perfect equilibria of the dynamic game obtain, all yield the unique equilibrium outcome $p^{*}$ specified above, however.

${ }^{6}$ Remember, the quality of a firm $j$ is a function of that firm's non-price characteristics and the preferences of the buyer, that is, $q_{j}=\alpha \mathbf{A}_{j}$. Each bidder clearly knows his own non-price characteristics, he does not know the preferences of the buyer, however. Hence he knows neither his own nor his rivals' quality. Our setup regarding the two extreme information regimes precisely fits the assumptions made in closely related literature, compare for example Gal-Or et al. (2007).
} 
winning probabilities are functions of only the firms' price bids. We assume that the winning probability $\tilde{P}_{k}$ of each firm $k$ is $\log$ concave in its final price quote. ${ }^{7}$ The expected profit $\tilde{\pi}_{j}$ of firm $j$ is given by

$$
\tilde{\pi}_{j}=\tilde{P}_{j}(\mathbf{p}) \cdot\left(p_{j}-c_{j}\right) .
$$

In analogy to the information case discussed above we now proceed and determine an equilibrium for the dynamic bidding game. For the sake of exposition, we again first assume that cost $c_{j}$ for $j=1, \ldots, J$ are known among firms (below we then also discuss the case of unknown costs of rivals). The unique equilibrium outcome $\mathbf{p}^{*}$ now is characterized by the following expression:

$$
p_{j}+\frac{\tilde{P}_{j}}{\partial \tilde{P}_{j} / \partial p_{j}}-c_{j}=0, \quad \forall j \in\{1, \ldots, J\} .
$$

That is, the equilibrium $b^{*}$ and the final equilibrium outcome $p^{*}$ are obtained analogous to the information case. However, the winning probabilities as perceived by the bidders, $\tilde{P}_{j}$, are now determined by (4).

- Robustness of the dynamic equilibrium. As shown above, when costs are known among firms, the dynamic bidding game can be solved by backwards induction. Initially submitted bids are irrelevant, and the final best response equilibrium outcome $\mathbf{p}^{*}$ can be shown to be unique. As we will argue subsequently, the above characterized outcome $\mathbf{p}^{*}$ also obtains in equilibrium when firms are incompletely informed with respect to their rivals' costs. Thus, we now consider the case where each firm has some private cost $c_{j}$ with distribution $F_{j}(c)$ with positive and bounded support $[\underline{c}, \bar{c}]$ for providing the service. Throughout the auction bidders $j=1, \ldots, J$ can now successively update their beliefs with respect to rivals' cost when observing the price-bids $b_{-j}(t)$ submitted by all rivals.

We first consider perfect Bayesian equilibria of the induced dynamic game. Notice that the final price vector $p^{*}$ characterized in expression (3) (respectively (6)) results as an equi-

\footnotetext{
${ }^{7}$ Notice that the logit framework referred to from section 6 onwards satisfies this assumption.
} 
librium outcome. An equilibrium strategy profile supporting this outcome is given as follows: on the equilibrium path bidders choose the currently (myopically) best response given all other currently active bids of the rivals (clearly this is also well defined in case no or only few active bids are already submitted when bidding just started). Beliefs with respect to rivals' costs are updated consistently, given the observed bids of rivals. The above characterized final price vector $\mathbf{p}^{*}$ results from the induced best response dynamic. There is a large class of beliefs and corresponding bids off the equilibrium path which support the equilibrium considered. $^{8}$ Notice, however, that for the case of fully rational bidders also other perfect Bayesian equilibria of the above specified auction framework involving different equilibrium outcomes obtain (for example, collusive equilibria).

As shown by Sobel and Wei (2010), furthermore, the restriction to markov perfect equilibria allows to restore uniqueness of the equilibrium also under incomplete information, and in this case $\mathbf{p}^{*}$ obtains as the unique equilibrium outcome of the dynamic game. Finally, notice that for the case of myopic bidders which always choose the myopic best response given the currently active bids of all rivals, the resulting best response dynamic yields the final price vector $p^{*}$ characterized in expressions (3) and (6) as the unique outcome. The same result also obtains for fully rational bidders which consider all their rivals to behave myopically (see for example Nisan et al., 2011). ${ }^{9}$

In sum, we see that for a large class of reasonable assumptions and standard equilibrium refinement choices the price vector $p^{*}$ characterized in expressions (3) and (6) always obtains as equilibrium outcome of the resulting dynamic bidding game, for many concepts considered as the unique outcome. We are thus confident that it provides a valuable and convincing reference for our further analysis.

- Comparing both information regimes. We are interested in whether the buyer

\footnotetext{
${ }^{8}$ For example, in case of deviation, players believe all rivals have the lowest possible cost $\underline{c}$ and choose their best replies accordingly, without further updating till bidding ends. This yields lower profits than along the equilibrium, and deviation is thus never profitable.

${ }^{9}$ Empirical evidence that players indeed significantly underestimate their rivals' rationality can be found, for example, in Weizsaecker (2003).
} 
prefers to disclose or to conceal non-price information. We assume that this decision has to be made prior to knowing the precise number and identity of the participating firms and their characteristics. In this case, the buyer prefers the information structure which gives him the highest expected utility. It is easy to show that there is no information structure which dominates the other. Appendix A.1 proofs this by example.

The central intuition is that the informational arrangement which creates the highest competitive pressure among firms is best for the buyer. Which information regime creates more competitive pressure as perceived by the firms depends on the specific situation considered, as we show. First, consider a situation where firms have similar production costs but are quite heterogenous with respect to how the buyer values their non-price characteristics. In short, using the definition of a firm's quality as the buyer's valuation of its non-price characteristics, that means a situation where firms have similar production costs but very different qualities. A regime which conceals non-price information suggests tough competition and induces more aggressive bidding. Second, consider a situation where firms have quite different production costs but quality differences are such as to compensate for those differences (that is, the more expensive producer also has higher quality). In this case, full revelation of non-price information induces more aggressive bidding. ${ }^{10}$ In the following section we offer an analytical illustration of these tradeoffs.

- Analytical illustration of tradeoffs and model mechanics. To illustrate the mechanics of our model in closed form we thus make the simplifying assumption that the difference of the error terms $\epsilon_{j}$ follows a uniform distribution. ${ }^{11}$ We then analyze bidding

\footnotetext{
${ }^{10}$ Notice that the fundamental tradeoffs in our setting are different from those occurring when comparing non-binding auctions with price only-mechanisms, as for example in Engelbrecht-Wiggans et al. (2007). Desirability in this case is strongly dependent on the correlation between cost and quality, since for the price only-mechanism considered buyers might be obliged to choose ex post suboptimal offers of low quality. In our setting buyers always choose the ex post optimal offers once bidding has stopped.

${ }^{11}$ Standard assumptions in discrete choice settings are that the difference of the error terms follows a normal or a logit distribution (which in turn follows from the assumptions that the error terms are normal respectively type I extreme value distributed). However, with these standard assumptions bidders' winning probabilities $P_{j}$ either cannot be expressed in closed form or contain exponential terms which lead to transcendental equations. Thus, for standard assumptions the first order conditions (3) respectively (6) cannot be solved analytically.
} 
in an auction where the buyer can choose among two firms only. ${ }^{12}$ Each firm has non-price characteristics $\mathbf{A}_{j}$. The respective preferences of the buyer are denoted by $\boldsymbol{\alpha}$. The buyer's valuation of a firm's non-price characteristics, that is its quality $q_{j}$, is given as $q_{j}=\boldsymbol{\alpha} \mathbf{A}_{j}$. We assume that $\epsilon_{2}-\epsilon_{1}$ shall follow a uniform distribution with mean zero and variance $\nu$ and $\tilde{\epsilon}_{2}-\tilde{\epsilon}_{1}$ shall follow a uniform distribution with mean zero and variance $\tilde{\nu}^{13}$ As in the no information case bidders are missing non-price information, they perceive the buyer's decision to be more noisy. Thus, we obtain $\tilde{\nu} \geq \nu$. Based on this setup, it is now possible to derive illustrative analytical results in closed form. The exact derivation can be found in appendix A.2.

Relationship between firms' equilibrium bids. Based on the first order conditions (3) and (6) we are able to derive the equilibrium bids in closed form (see appendix A.2). We denote the equilibrium bids in the information case by $p_{i}^{*}$, and those in the no information case by $\tilde{p}_{i}^{*}$ :

$$
\begin{aligned}
& p_{1}^{*}=\tilde{p}_{1}^{*}-\frac{1}{3}\left(q_{2}-q_{1}\right)-\sqrt{3}(\sqrt{\tilde{\nu}}-\sqrt{\nu}), \\
& p_{2}^{*}=\tilde{p}_{2}^{*}+\frac{1}{3}\left(q_{2}-q_{1}\right)-\sqrt{3}(\sqrt{\tilde{\nu}}-\sqrt{\nu}) .
\end{aligned}
$$

The intuition behind expressions (7) and (8) is straightforward (without loss of generality let $\left.q_{1}<q_{2}\right)$ : The first term added to $\tilde{p}_{2}^{*}$ respectively subtracted from $\tilde{p}_{1}^{*}$ in expressions $(7)$ and (8) captures that in case of disclosed non-price information firms are aware of firm two's competitive advantage in terms of quality: The net competitive pressure on the low-quality firm (firm one) is higher then in case of concealed non-price information, while that on the high-quality firm (firm two) is lower. The last term in expressions (7) and (8) captures that

\footnotetext{
${ }^{12}$ We furthermore assume that the value of the outside option is so low that the induced upper limit of the prices of firm 1 and 2 is above the equilibrium prices and the outside option is never chosen. An explicit consideration of the outside option would make our analysis more complicated without delivering further insights.

${ }^{13}$ That is, $\left(\epsilon_{2}-\epsilon_{1}\right) \sim U[-\sqrt{3 \nu}, \sqrt{3 \nu}]$ and $\left(\tilde{\epsilon}_{2}-\tilde{\epsilon}_{1}\right) \sim U[-\sqrt{3 \tilde{\nu}}, \sqrt{3 \tilde{\nu}}]$.
} 


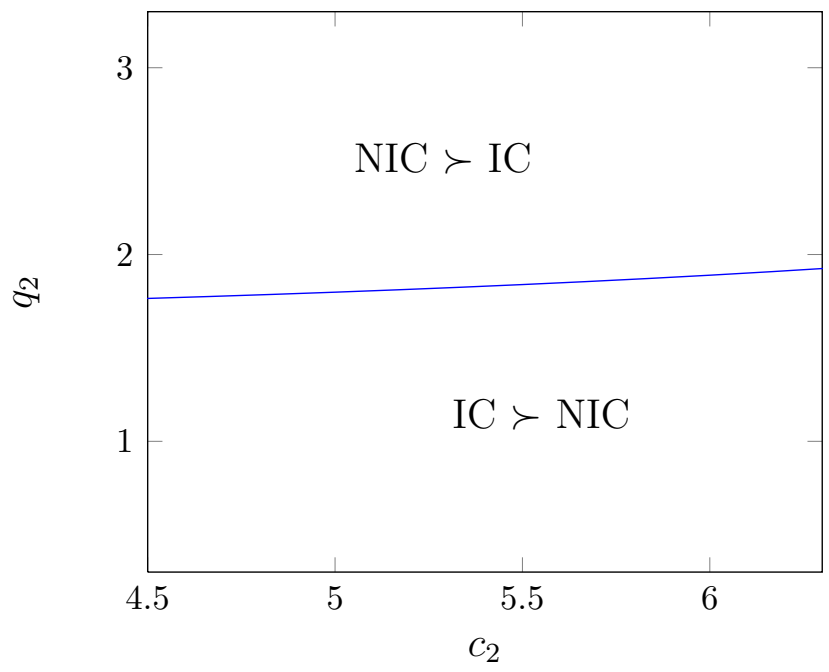

Figure 1: The preferences of the buyer regarding the information structure as a function of the auction parameters. The graph shows the indifference line of the buyer. The indifference line represents the parameter set at which the buyer is indifferent between disclosing and concealing non-price information. Our parameter assumptions here $\left(c_{1}=4.5\right.$ and $\left.q_{1}=0.3\right)$ are made with a view to our application. For all $q_{2}-c_{2}$-combinations above the indifference line the buyer prefers to conceal non-price information. For all combinations below he prefers to disclose non-price information.

in case of concealed non-price information firms perceive the buyer's decision to be more noisy and thus increase their price bids. That is, the equilibrium offer of the low quality firm is strictly higher for concealed information $\left(p_{1}^{*}>\tilde{p}_{1}^{*}\right)$, the impact on the equilibrium offer of the high quality firm is ambiguous, it is lower for large enough quality differential, however. Thus, concealment of quality information is beneficial for the buyer if and only if this leads to a reduced equilibrium offer of the high quality firm and additionally the buyer finds it ex post optimal to then also choose the high quality buyer.

Relationship between buyer's expected utilities. The relationship between the expected utility of the buyer in the information case, EU, and that in the no information case, $\widetilde{\mathrm{EU}}$, is given by

$$
\begin{aligned}
\mathrm{EU}-\widetilde{\mathrm{EU}}=\frac{1}{3 \sqrt{12 \nu}}\left(q_{2}-q_{1}\right)\left[\left(c_{2}-c_{1}\right)-2\left(q_{2}-q_{1}\right)\right] \\
+3(2 \sqrt{\nu \tilde{\nu}}+\tilde{\nu}-3 \nu) \\
\quad+\left(\frac{\sqrt{\tilde{\nu}}}{2 \sqrt{\nu}}-\frac{1}{2}\right)\left(c_{2}+c_{1}-q_{2}-q_{1}\right) .
\end{aligned}
$$


Equation (9) shows that the net change in the expected utility of the buyer depends on three factors: The first term captures the tradeoff between the competitive advantage of the low-cost firm and that of the high-quality firm. If the difference in costs is small but that in qualities is very high, disclosure of non-price information weakens competition because firms become aware of the high-quality firm's large net advantage. If in contrast the difference in costs is very high and that in qualities small, disclosure of non-price information strengthens competition as it mitigates the net advantage of the low-cost firm. The second term captures that in the no information case firms perceive the decision of the buyer to be more noisy. In the no information case they thus demand higher prices which in turn decreases buyer's welfare. The third term weighs the effect of uncertainty (term two) against that of quality information (term one). The weight of either effect depends on how strong relative to costs firms' pricing decisions are influenced by non-price information. The smaller the influence of non-price information, the more the effect of noise in the buyer's decision outweighs that of non-price information.

The graph in figure 1 illustrates how the buyer's preferences regarding the information structure change as a function of the auction parameters, namely firms' costs and qualities. The parameter sizes used for this example resemble parameter sizes from our application. ${ }^{14}$ The important take-away is that which information structure to choose for a specific application is not clear ex ante but depends on the setting. In general, if the difference in qualities is high and that in cost is low, the buyer prefers to conceal non-price information. In contrast, if the difference in qualities is low and that in cost is high, the buyer prefers to disclose non-price information.

\footnotetext{
${ }^{14}$ The average value of $\boldsymbol{\alpha} \mathbf{A}_{j}$ in our data (that is, the average quality $q_{j}$ ) is 0.3 . The average (estimated) cost are $€ 450$. In "utility-units" this is 4.5 (which equals the average value of $\rho c_{j}$ ). For our example, we set $c_{1}=4.5$ and $q_{1}=0.3$.
} 


\section{Data}

We have available an extensive dataset from a popular European online procurement platform. On this platform private customers tender jobs ranging from construction over general repair and renovation to teaching. Jobs are awarded through an open non-binding auction.

The exact procedure is as follows: A private customer (the buyer) posts a description of the job he wants to procure. This description is entered into a free-text field and usually contains job details (for example, the area to be painted, whether or not cleaning is required, and so on), the job site, a price expectation (termed "startprice" in the following), and an announcement of the time span during which tradesmen (the bidders) can put forward quotes. All this information is available to all tradesmen registered at the platform. During the defined time span all interested tradesmen can publicly announce prices for which they are willing to do the offered job. Announced prices can be changed at any point during the auction. The current price quote of each bidder and all his non-price characteristics are publicly observable on the website. The non-price characteristics of a bidder include the number of positive and negative ratings the bidder received so far, his home location, qualifications like the possession of certain degrees, his area of expertise, and so on. At the end of the auction the buyer is free to award the job to one of the bidders or to withdraw his offer. In case of an award the platform obtains a certain percentage of the successful bid as commission.

We have available data on auctions which were conducted during the years 2007 and 2008. In this time span the auction platform experimented with some rule changes. In order to exclude the possibility that our results are influenced by these rule changes we focus our analysis on auctions which took place during the second half of the year 2008. In this period there were only minor rule changes, like for example a slight reduction of the time span after which the buyer has to decide whether to withdraw his offer or award the job to one of the participating bidders. Minor changes like these should have no effect on our results. 


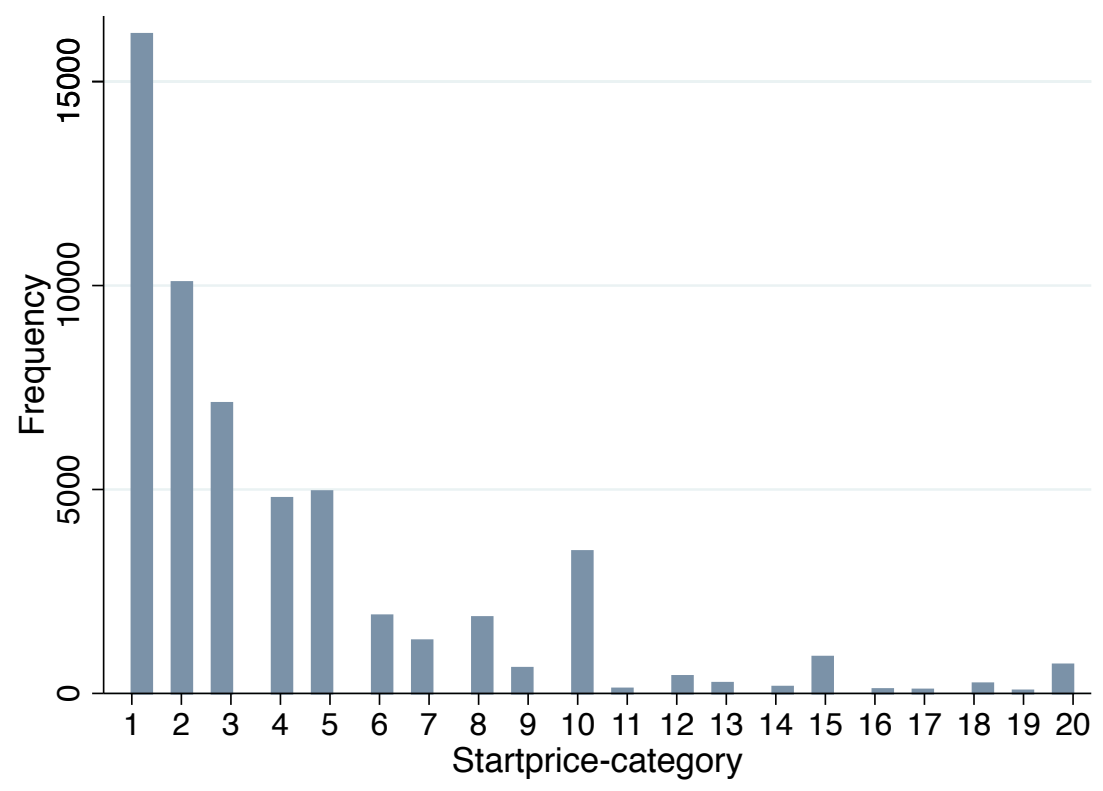

Figure 2: Distribution of auctions over startprice categories. Displayed is the distribution of all auctions which were conducted in the three largest job-categories ("moving", "painting" and "car") during the second half of 2008 over all startprice-categories. Startprice-category 1 ranges from $€ 1$-100, startpricecategory 2 ranges from $€ 101-200$, and so on.

The auctions we observe in the second half of 2008 are grouped into 32 job-categories. The three most frequent job-categories are "moving" (14.1\% of all auctions), "painting" (8.4\% of all auctions) and "car repairs" (7.0\% of all auctions). We concentrate our following analysis on these three job-categories. Besides by the kind of job offered, auctions are differentiated by the value of the jobs offered. We use the price expectation the buyer states at the beginning of the auction (the startprice) as a proxy for the value of the job offered. ${ }^{15}$ Startprices can be chosen freely but are typically set in multiples of $€ 100$ (respectively $€ 50$ for auctions with values below $€ 500)$. We sort the auctions into different startprice-categories: Category 1 ranges from $€ 1-100$, category 2 from $€ 101-200$, and so on. Figure 2 depicts the distribution of the auctions over these startprice-categories for the three most frequent auction categories. The numbers show that $38 \%$ of all auctions have startprices between $€ 1-100$, and of these

\footnotetext{
${ }^{15}$ The level of the startprices put forward by the buyers is highly correlated with the level of the prices the bidders put forward, which reassures us that startprices are indeed good proxies for the value of the jobs procured. Note also that the startprice is set purely for informational reasons, it neither puts any restriction on bids submitted nor on the award decision made by the potential buyer.
} 


\begin{tabular}{|c|c|c|c|c|c|}
\hline "Moving" & Mean & $\mathrm{SD}$ & Median & Min & Max \\
\hline Nbr. of auctions & 16,841 & & & & \\
\hline Nbr. of bidders & 4,564 & & & & \\
\hline Nbr. of buyers & 15,076 & & & & \\
\hline Nbr. of bidders per auction & 5.1 & 3.1 & 4 & 2 & 27 \\
\hline Bid amount & 556.7 & 463.7 & 450 & 1 & 3000 \\
\hline Nbr. of auction participations per bidder & 5.3 & 35.8 & 1 & 1 & 1748 \\
\hline Auctions per buyer & 1.1 & 0.5 & 1 & 1 & 23 \\
\hline Auction duration (days) & 10.6 & 9.6 & 8.7 & 0 & 144.0 \\
\hline Last bid placement (hours till auction end) & 88.5 & 160.8 & 20.0 & 0 & $1,883.7$ \\
\hline "Painting" & Mean & SD & Median & Min & Max \\
\hline Nbr. of auctions & 11,434 & & & & \\
\hline Nbr. of bidders & 5,800 & & & & \\
\hline Nbr. of buyers & 10,614 & & & & \\
\hline Nbr. of bidders per auction & 6.4 & 4.2 & 5 & 2 & 31 \\
\hline Bid amount & 606.2 & 496.3 & 450 & 0 & 3000 \\
\hline Nbr. of auction participations per bidder & 5.2 & 21.9 & 1 & 1 & 793 \\
\hline Auctions per buyer & 1.1 & 0.3 & 1 & 1 & 8 \\
\hline Auction duration (days) & 11.4 & 9.3 & 10 & 0 & 120.0 \\
\hline Last bid placement (hours till auction end) & 84.2 & 162.4 & 12.3 & 0 & $1,891.8$ \\
\hline "Car" & Mean & SD & Median & Min & $\operatorname{Max}$ \\
\hline Nbr. of auctions & 3,413 & & & & \\
\hline Nbr. of bidders & 1,541 & & & & \\
\hline Nbr. of buyers & 3,216 & & & & \\
\hline Nbr. of bidders per auction & 2.8 & 1.2 & 2 & 2 & 12 \\
\hline Bid amount & 398.0 & 449.4 & 250 & 1 & 3000 \\
\hline Nbr. of auction participations per bidder & 2.7 & 12.4 & 1 & 1 & 397 \\
\hline Auctions per buyer & 1.1 & 0.3 & 1 & 1 & 4 \\
\hline Auction duration (days) & 15.3 & 12.1 & 14 & 0 & 118.1 \\
\hline Last bid placement (hours till auction end) & 150.8 & 215.5 & 53.2 & 0 & $1,786.7$ \\
\hline
\end{tabular}

Table 1: Descriptive statistics for auctions from job categories "moving", "painting", and "car". The table displays descriptive statistics for auctions from the three most popular job categories ("moving", "painting", and "car"). Considered are all auctions with startprices ranging from $€ 1-2000$ and with at least two participating bidders.

auctions again $60 \%$ have a startprice of $€ 50$ or less. We expect bidding behavior in these very low valued auctions to be fundamentally different from bidding behavior in auctions with higher stakes and thus drop all auctions with startprices less or equal to $€ 100$ from our analysis.

For every auction in each job-startprice-category we have available information about the number and the identities of the participating bidders, the prices put forward, the bidders' non-price characteristics (like the number of positive and negative ratings, the possession 

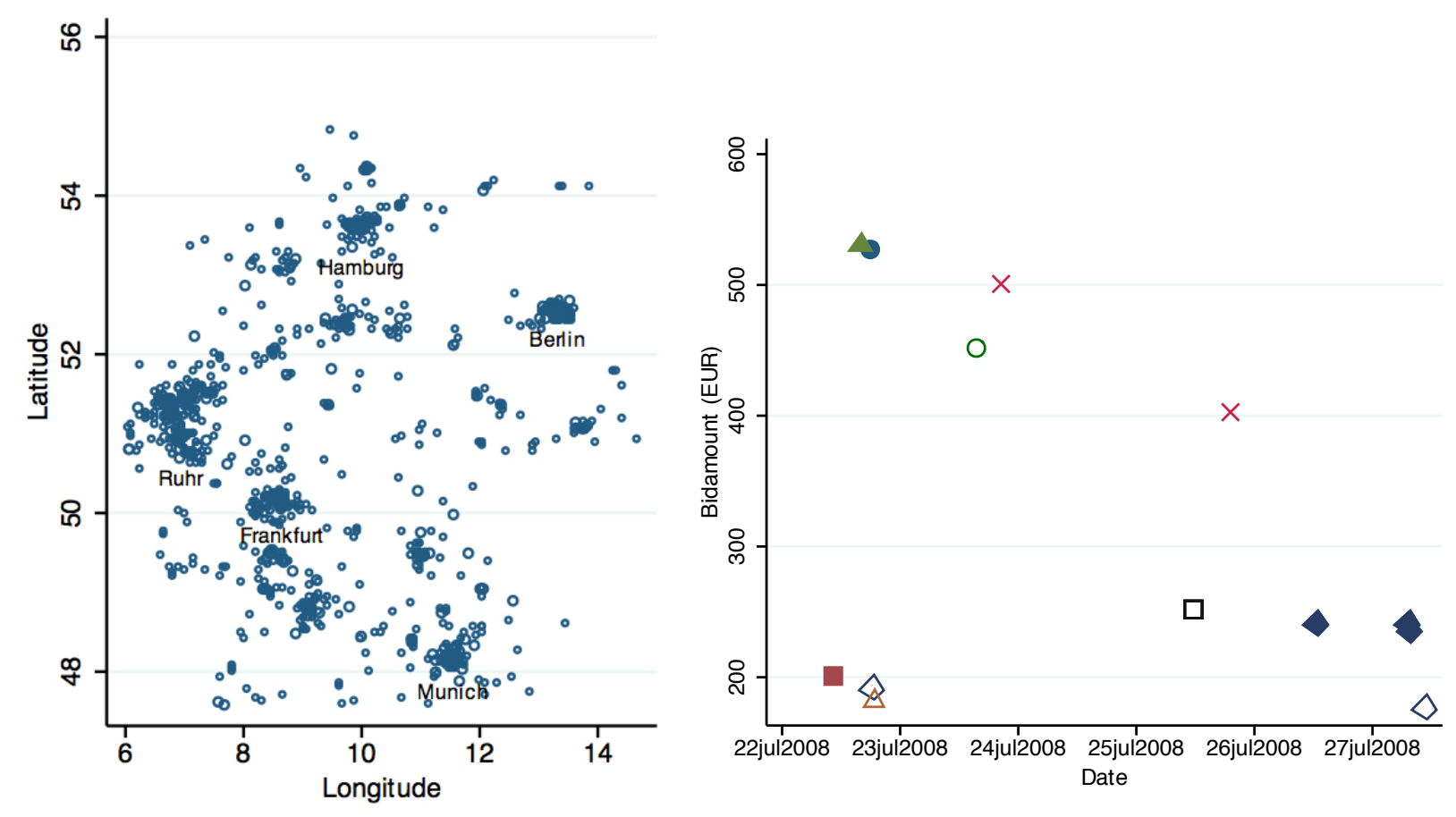

Figure 3: Spatial distribution of auctions and exemplary bidding process. On the left, the spatial distribution of auctions in Germany is displayed. On the right, an example of a typical bidding process is shown. The different symbols stand for different bidders, the auction is from the job category "painting", and the startprice set was $€ 200$.

of certain degrees and qualifications, and so on) and the final choice of the potential buyer (including whether he chose to withdraw his job offer). We use only auctions in which at least two bidders participate. Descriptive statistics for each auction-category are given in table 1. The left part of figure 3 shows the spatial distribution of all auctions conducted, the right part gives an exemplary impression of the course of an auction.

On the auction platform we have our data from both buyers and bidders are fully informed about each bidders' non-price characteristics. We are interested in what would happen to the welfare of the buyers if this non-price information was concealed from the bidders. Our theoretical considerations in section 2 show that, among other things, the answer depends on how important bidders' non-price characteristics are to buyers. We think it is reasonable to expect buyers' preferences $\boldsymbol{\alpha}$ regarding bidders' non-price characteristics to depend both on the job category and on the value of the job offered. For example, whether a bidder has 
undergone professional training should matter more for jobs from the "car repairs" category than for jobs from the "moving" category. Similarly, whether a bidder has liability insurance might matter more for a buyer when he procures a high-value job than when he procures a low-value job. To capture that the choice behavior of a buyer (and in consequence the behavior of the bidders) possibly depends on the type and the value of the job offered, we will perform separate analyses for the three most frequent job categories ("moving", "painting", "car repairs") and for each of the three most frequent startprice-categories (2, 3 and 5). ${ }^{16}$

For a sample of around two-thousand auctions from job category "painting" we manually extracted information about cost factors from the job descriptions. These cost factors include for example the area to be painted, whether paint is provided by the buyer, and so on. We do not need this information for our counterfactual analysis in section 6 , where for each job-startprice-category we analyze the change in aggregate welfare of the buyers in case non-price information gets concealed. However, before doing our counterfactual analysis in section 6 , in section 5 we use information about these cost factors to verify a fundamental assumption of our counterfactual analysis: That bidders know about the preferences of the buyers regarding their non-price characteristics and that thus our model for the case of disclosed non-price information describes their behavior.

\section{Analysis of Buyers' Preferences}

Besides price information buyers have available information about the non-price characteristics of the bidders. We assume that when making their decisions buyers take into account both price and non-price information. In particular, we assume that a buyer's ranking of a given bidder depends on both the price that bidder puts forward and how he values that bidder's non-price characteristics. With $\mathbf{A}_{j}$ denoting the vector of bidder $j$ 's non-price characteristics and $\boldsymbol{\alpha}$ denoting the vector of the buyer's respective preferences, we assume

\footnotetext{
${ }^{16}$ For the sake of completeness the results for startprice-category 4 are given in tables 8 and 9 in the appendix.
} 
the buyer's valuation of bidder $j$ 's non-price characteristics (that is, bidder $j$ 's quality) to be equal to $\boldsymbol{\alpha} \mathbf{A}_{j}$. We observe each bidder's non-price characteristics, but we do not observe the preferences of the buyers. In this section we use a logit discrete choice model to elicit buyers' preferences $\boldsymbol{\alpha}$.

Econometric model. For a given auction $n$ we model a buyer's decision as a discrete choice among all participating bidders and an outside option. We assume the buyer to base his decision among bidders on both their prices and their non-price characteristics. Bidders' non-price characteristics comprise binary characteristics, indicating for example the possession of certain degrees, discrete characteristics, like the number of positive and negative ratings, and a continuous measure for the distance between a bidder's home location and the job site. ${ }^{17}$

We estimate buyers' preferences along the lines of the model we developed in section 2: In a given auction $n$, a buyer's utility from choosing bidder $j$ is assumed to be linearly dependent on the bidder's price $p_{n j}$, how he values the bidder's non-price characteristics, and an error term $\epsilon_{n j}$. We assume that the buyer's valuation of a bidder's non-price characteristics is a linear function of that bidder's non-price characteristics and the buyer's respective preferences, that is $\boldsymbol{\alpha} \mathbf{A}_{n j}{ }^{18}$ With $\rho$ denoting the price elasticity of the buyer in auction $n,{ }^{19}$ the utility he derives from each of the $J_{n}$ participating bidders can explicitly be formulated

\footnotetext{
${ }^{17}$ The distance measure is constructed from the buyers' and the bidders' zip-codes.

${ }^{18}$ For simplicity, we are assuming that each buyer has the same preferences $\boldsymbol{\alpha}$. We could replace this assumption by assuming that the preferences $\boldsymbol{\alpha}$ of the buyers follow a normal distribution, and accordingly estimate a mixed logit model. However, this more involved approach does not deliver significantly different results.

${ }^{19}$ We use a logit discrete choice model to elicit the preferences of the buyers. The scale of the logit discrete choice model is determined by the variance of the error terms $\epsilon_{j}$. Thus, for our empirical analysis we can no longer use the convenient normalization of the price coefficient $\rho$ to -1 .
} 


$$
\begin{aligned}
u_{n 0} & =\epsilon_{n 0} \\
u_{n 1} & =t+\rho p_{n 1}+\boldsymbol{\alpha} \mathbf{A}_{n 1}+\epsilon_{n 1} \\
& \vdots \\
u_{n J_{n}} & =t+\rho p_{n J_{n}}+\boldsymbol{\alpha} \mathbf{A}_{n J_{n}}+\epsilon_{n J_{n}} .
\end{aligned}
$$

The constant $t$ captures the value of the outside option. It holds that the lower $t$ the higher is the value of the outside option. The error terms $\epsilon_{n j}$ capture unobserved influences on the buyer's decision unrelated to bidders' prices or their observed non-price characteristics. The buyer is assumed to choose the bidder which offers him the highest utility. By assuming the error terms $\epsilon_{n j}$ to be independently, identically type I extreme value distributed we obtain the standard logit model: The choice probabilities are given as

$$
P_{n j}= \begin{cases}\frac{1}{1+\sum_{k=1}^{J_{n}} e^{t+\rho p_{n k}+\alpha \mathbf{A}_{n k}}} & \text { if } j=0, \\ \frac{e^{t+\rho p_{n j}+\alpha \mathbf{A}_{n j}}}{1+\sum_{k=1}^{J_{n}} e^{t+\rho p_{n k}+\alpha \mathbf{A}_{n k}}} & \text { if } j \in\left\{1, \ldots, J_{n}\right\} .\end{cases}
$$

Estimates of the model parameters $\{\rho, \boldsymbol{\alpha}\}$ can be obtained by maximizing the likelihood

$$
L=\prod_{n=1}^{N} \prod_{j=0}^{J_{n}}\left(P_{n j}\right)^{y_{n j}}, \quad y_{n j}= \begin{cases}1 & \text { if alternative } j \text { is chosen in auction } n \\ 0 & \text { otherwise }\end{cases}
$$

Estimation results. We estimate our model for each combination of the job categories "moving", "painting", "car repairs" and the startprice-categories 2, 3, 5. Table 2 displays the results for startprice category 2 (which covers all auctions with startprices ranging from $€ 101-200)$ and all job categories. Table 3 displays the results for job category "moving" and all startprice-categories. The results for all other job-startprice-categories considered are similar and due to reasons of brevity not displayed here. 


\begin{tabular}{|c|c|c|c|}
\hline \multirow{2}{*}{$\begin{array}{l}\text { Covariates in } \\
\text { buyer's utility fct. }\end{array}$} & \multicolumn{3}{|c|}{ Job category } \\
\hline & "Moving" & "Painting" & "Car" \\
\hline Bid amount $(€ 100)$ & $-1.467^{* * *}$ & $-1.552^{* * *}$ & $-1.426^{* * *}$ \\
\hline Nbr. of positive ratings $(\ln )$ & $0.211^{* * *}$ & $0.250^{* * *}$ & $0.281^{* * *}$ \\
\hline Nbr. of negative ratings (ln) & $-0.171^{* * *}$ & $-0.240^{* * *}$ & $-0.386^{* * *}$ \\
\hline Nbr. of employees & -0.0436 & -0.0832 & -0.119 \\
\hline Liability insurance & $0.303^{*}$ & 0.163 & -0.0436 \\
\hline Distance $(\mathrm{km}, \mathrm{ln})$ & $-0.132^{* * *}$ & $-0.165^{* * *}$ & -0.0540 \\
\hline Certified membership & 0.0113 & 0.0216 & 0.0142 \\
\hline Trade License & -0.0256 & -0.0480 & -0.0147 \\
\hline Master craftsman company & -0.182 & -0.0000365 & 0.0323 \\
\hline Engineer & 0.0000382 & -0.0804 & 0.437 \\
\hline Technician & $1.337^{*}$ & $1.287^{*}$ & 0.118 \\
\hline Senior journeyman company & 0.151 & -0.194 & -0.298 \\
\hline Other certifications & $-0.274^{* * *}$ & 0.142 & -0.143 \\
\hline Craftsman card & $-0.646^{*}$ & -0.0834 & 0.0690 \\
\hline Certified registrations & 0.140 & -0.0993 & 0.396 \\
\hline In craftsmen register & 0.0529 & 0.0492 & -0.140 \\
\hline Constant & $1.759^{* * *}$ & $2.051^{* * *}$ & $1.778^{* * *}$ \\
\hline Nbr. of observations & 14106 & 10849 & 1896 \\
\hline Nbr. of auctions & 2691 & 1703 & 474 \\
\hline
\end{tabular}

Table 2: Preference estimates for startprice-category $\mathbf{2}$ and all job-categories. The table gives the results of the estimation of the logit discrete choice model given by equation (10) for startprice-category 2 and all job-categories. Displayed are the coefficients on the covariates in the utility function of the buyers. Significance niveaus are reported by stars: ***: $1 \%, * *: 5 \%, *: 10 \%$.

The estimates for all job-startprice-categories exhibit the same general pattern: The coefficients on the price coefficient, the ratings coefficients and the constant are highly significant, while the coefficients on the other covariates are mostly insignificant. That does not come as a surprise, as the information about bidders most prominently displayed in the auction overview screen are bidders' prices and the number of their positive and negative ratings. Information on bidders' other non-price characteristics like the possession of certain degrees or the membership in certain institutions is only available after some additional clicks. The constant is highly significant because in about half of all auctions buyers choose to withdraw their job offers. It holds that the higher the value of the constant (which appears in the utility a buyer derives from a certain bidder), the lower is the value of the outside option.

The numbers given in tables 2 and 3 are coefficient estimates and as such have no direct 


\begin{tabular}{|c|c|c|c|}
\hline \multirow{2}{*}{$\begin{array}{l}\text { Covariates in } \\
\text { buyer's utility fct. }\end{array}$} & \multicolumn{3}{|c|}{ Startprices } \\
\hline & $€ 101-200$ & $€ 201-300$ & $€ 401-500$ \\
\hline Bid amount $(€ 100)$ & $-1.467^{* * *}$ & $-1.148^{* * *}$ & $-0.585^{* * *}$ \\
\hline Nbr. of positive ratings $(\ln )$ & $0.211^{* * *}$ & $0.226^{* * *}$ & $0.251^{* * *}$ \\
\hline Nbr. of negative ratings $(\ln )$ & $-0.171^{* * *}$ & $-0.182^{* * *}$ & $-0.246^{* * *}$ \\
\hline Nbr. of employees & -0.0436 & -0.0757 & -0.0150 \\
\hline Liability insurance & $0.303^{*}$ & $0.395^{*}$ & $0.657^{*}$ \\
\hline Distance $(\mathrm{km}, \mathrm{ln})$ & $-0.132^{* * *}$ & $-0.129^{* * *}$ & $-0.128^{* * *}$ \\
\hline Certified membership & 0.0113 & 0.115 & 0.0226 \\
\hline Trade License & -0.0256 & 0.0271 & 0.0517 \\
\hline Master craftsman company & -0.182 & -0.307 & $-0.843^{* * *}$ \\
\hline Engineer & 0.0000382 & 0.0226 & 0.00795 \\
\hline Technician & $1.337^{*}$ & 0.645 & $1.701^{* * *}$ \\
\hline Senior journeyman company & 0.151 & 0.0530 & -0.383 \\
\hline Other certifications & $-0.274^{* * *}$ & 0.0553 & $0.180^{* *}$ \\
\hline Craftsman card & $-0.646^{*}$ & 0.0461 & 0.325 \\
\hline Certified registrations & 0.140 & -0.280 & 0.381 \\
\hline In craftsmen register & 0.0529 & -0.158 & -0.226 \\
\hline Constant & $1.759^{* * *}$ & $2.122^{* * *}$ & $1.022^{* *}$ \\
\hline Nbr. of observations & 14106 & 10911 & 10908 \\
\hline Nbr. of auctions & 2691 & 1813 & 1517 \\
\hline
\end{tabular}

Table 3: Preference estimates for job-category "moving" and all startprice-categories. The table gives the results of the estimation of the logit discrete choice model given by (10) for job-category "moving" and all startprice-categories. Displayed are the coefficients on the covariates in the utility function of the buyers. Significance niveaus are reported by stars: ***: $1 \%,{ }^{* *}: 5 \%, *: 10 \%$.

interpretation. In order to get an impression of the effect of a decrease of a bidder's price by $€ 10$ or an increase in his positive or negative ratings, we computed average marginal effects. For startprice-category 2 (table 2), we find that a decrease of a bidder's price by $€ 10$ increases his winning probability by around $2 \%$. This holds for all job-categories. Over all job-categories, one additional positive rating increases a bidder's winning probability by around 1\%, while an additional negative rating decreases a bidder's winning probability by around $2 \%$. The influence of the number of ratings is most pronounced for category "car repairs" , where one additional negative rating lowers a bidder's winning probability by around $4 \%$.

For job-category "moving" (table 3), with respect to ratings we get the result that for all startprice-categories an additional positive rating increases a bidder's winning probability 
by around 1\%, while an additional negative rating decreases a bidder's winning probability by around $2 \%$. As might be expected, we find that the effect of a decrease in a bidder's price depends on the value of the auction (as is proxied for by the startprice) - the higher the value of the auction, the lower the effect of a certain price decrease. In particular, we find that while a price decrease of $€ 10$ increases a bidder's winning probability by $2 \%$ for startprice-category 2, it only increases a bidder's winning probability by less than $1 \%$ for startprice category 5 .

We think it is reasonable to assume that on average jobs from categories "moving" and "painting" require less skills than jobs from the category "car repair". That is, for the latter category we expect bidders non-price characteristics to be more important for the decisions of the buyers. This presumption is confirmed by our results - a look at table 2 shows that the influence of a bidder's ratings relative to his price (as expressed by the relationship between the coefficient on a bidder's positive respectively negative ratings and the price coefficient) is indeed significantly higher for category "car repairs" than for categories "moving" and "painting".

The results discussed above hinge on the assumption that the error terms $\epsilon_{n j}$ in (10) are neither correlated with the prices $p_{n j}$ nor with bidders' attributes $\mathbf{A}_{n j}$. In other words, for our estimation results to be consistent there must be no unobserved factors which influence buyers' utilities in a way systematically connected to our observables. However, as we analyze auctions conducted on an online marketplace, and as we were provided with very detailed recordings of these auctions, we are convinced that we are able to control for all factors which have a systematic influence on the buyers' utilities: Our data contains exactly the amount of information about bidders buyers have available when making their decisions. Thus, there should be no influences on buyers' utilities which are both unobserved and in some way systematically connected to bidders' attributes. 


\section{Analysis of Bidders' Information State}

In section 2 we proposed two models to describe bidders' behavior in open non-binding auctions. On the auction platform we have our data from bidders are informed about each other's non-price characteristics. We would thus expect their behavior to be in line with the predictions of our information case model. To verify this hypothesis, in this section we use a reduced form model to verify whether the observed behavior of the bidders is indeed in

line with the predictions of our information case model. In particular, we exploit contrasting testable predictions of the framework for the case of disclosed and that of concealed non-price information: If bidders behave according to our information case model, they should react to changes in the quality composition of an auction. In particular, in reaction to the appearance of a high quality opponent they should strongly decrease their prices. In contrast, if bidders behave according to our no information case model, they should show no reaction at all.

Econometric model. We test for these contrasting implications by using the following reduced form model of bidders' pricing behavior:

$$
p_{n j}=\boldsymbol{\xi} \mathbf{K}_{n j}+\beta S_{n j}+a_{j}+\nu_{n j}
$$

This model describes bidders' pricing behavior along the lines of our theoretical frameworks from section 2. Basically, we assume that the price bidder $j$ puts forward in auction $n$ depends on his cost $c_{n j}$ and, in case of disclosed quality information, on his quality relative to that of his rivals. We assume the $\operatorname{cost} c_{n j}$ to depend both on observable cost factors $\mathbf{K}_{n j}$ and on unobserved opportunity costs of bidder $j$. How bidder $j$ fares in terms of the buyer's valuation of his non-price characteristics (that is, in terms of quality) relative to his rivals is assumed to depend on bidder $j$ 's strength in terms of quality relative to the whole population of bidders and an unobserved auction-specific deviation. Bidder $j$ 's overall strength in terms of quality is captured in the bidder specific constant $a_{j}$. The error term $\nu_{n j}$ captures both bidder $j$ 's opportunity costs for the job offered in auction $n$ and the auction-specific deviation 
to this "overall strength".

The binary variable $S_{n j}$ indicates whether bidder $j$ faces a rival bidder who is strong in terms of quality. We know from our theoretical considerations that if in case of disclosed quality information a rival of bidder $j$ was replaced by one who is stronger in terms of quality, bidder $j$ should react by decreasing his price. In contrast, if quality information was concealed, bidder $j$ should show no reaction. That means we expect $\beta<0$ if bidders behave according to our information case model, and $\beta=0$ otherwise.

- Identification strategy. We restrict our analysis to bidders which are observed to participate in several auctions. In doing so, we are able to estimate equation (11) by meandifferencing (that is, employing a fixed effects estimator). By that we get rid of the individual specific and unobserved constants $a_{j}$. The assumption which has to hold for our estimates to be consistent is that the $\epsilon_{n j}$ are mean-independent from the observable cost elements $\mathbf{K}_{n j}$ and the strong rival indicator $S_{n j}$. As we will discuss in more detail below, this assumption is likely to hold in our case.

- Estimation. Our results from section 4 show that throughout all job-startprice categories the decisions of the buyers are strongly influenced by the number of positive and negative ratings of bidders. Thus, we define that a given bidder $j$ encounters a strong rival in auction $n$ if at least one of the other bidders in auction $n$ has a difference of positive and negative ratings of at least $90: 20$

$$
S_{n j}= \begin{cases}1 & \text { if encounter with strong bidder (ratings difference } \geq 90) \\ 0 & \text { otherwise }\end{cases}
$$

In order to estimate equation (11) we need information about cost factors $\mathbf{K}_{n j}$. Thus, we have to restrict our estimation to the subset of auctions from job category "painting" for which we manually collected cost information. In order to estimate equation (11) by a fixed

\footnotetext{
${ }^{20}$ For comparison: The mean difference of positive and negative ratings in our sample is 5.8 . $1 \%$ of the bidders in our sample have a ratings difference of at least 90 .
} 


\begin{tabular}{|c|c|c|c|}
\hline $\begin{array}{l}\text { Dependent variable: } \\
\text { Bid amount of bidder } j \\
\text { in auction } n\end{array}$ & $(1)$ & $(2)$ & $(3)$ \\
\hline $\begin{array}{l}\text { Encounter with } \\
\text { strong rival (dummy) }\end{array}$ & $\begin{array}{r}-82.85^{* * *} \\
(14.89)\end{array}$ & $\begin{array}{r}-91.57^{* * *} \\
(17.73)\end{array}$ & $\begin{array}{r}-93.79^{* * *} \\
(17.77)\end{array}$ \\
\hline \multicolumn{4}{|l|}{ Controls: } \\
\hline Area to paint $\left(\mathrm{m}^{2}\right)$ & $1.72^{* * *}$ & $1.74^{* * *}$ & $1.61^{* * *}$ \\
\hline Area to paper $\left(\mathrm{m}^{2}\right)$ & $1.41^{* * *}$ & $1.28^{* * *}$ & $1.29^{* * *}$ \\
\hline Paper removal $\left(\mathrm{m}^{2}\right)$ & $2.72^{* * *}$ & $2.89^{* * *}$ & $2.54^{* * *}$ \\
\hline Cleaning (dummy) & $77.63^{* * *}$ & $64.08^{* *}$ & $54.01^{*}$ \\
\hline Reparation (dummy) & $40.60^{* * *}$ & $56.39^{* * *}$ & $42.30^{* * *}$ \\
\hline Priming (dummy) & $124.60^{* * *}$ & $125.44^{* * *}$ & $114.41^{* * *}$ \\
\hline No. of windows & 10.41 & 11.00 & 13.39 \\
\hline No. of window frames & 34.31 & 25.40 & 19.41 \\
\hline No. of doors & $45.78^{* * *}$ & $46.23^{* * *}$ & $42.22^{* * *}$ \\
\hline No. of door frames & $17.72^{* * *}$ & $18.56^{* * *}$ & $18.21^{* * *}$ \\
\hline Nbr. of radiators & $85.33^{* * *}$ & $85.58^{* * *}$ & $78.91^{* * *}$ \\
\hline Paint by contractor (dummy) & $25.99^{* *}$ & 14.97 & $18.89^{*}$ \\
\hline Varnish by contractor (dummy) & $125.58^{*}$ & 116.82 & 102.01 \\
\hline Distance $(\mathrm{km})$ & $1.15^{* * *}$ & $1.17^{* * *}$ & $.76^{* * *}$ \\
\hline Dummies for nbr. of bidders & & $\mathrm{X}$ & $\mathrm{X}$ \\
\hline Dummies for region & & $\mathrm{X}$ & $\mathrm{X}$ \\
\hline Controls for bidder composition & & & $\mathrm{X}$ \\
\hline Bidder FE's & X & X & $\mathrm{X}$ \\
\hline $\mathrm{R}^{2}$ & 0.292 & 0.300 & 0.341 \\
\hline $\mathrm{N}$ & 9,546 & 9,546 & 9,546 \\
\hline
\end{tabular}

Table 4: Identification of bidders' reaction to a strong rival. The table shows the results of a fixed effects estimation of the reduced-form model (11). The dependent variable is bid amount. Covariates are a dummy indicating the appearance of strong rival (a rival with a difference between positive and negative ratings of at least 90) and cost controls. The panel consists of 941 bidders who on average took part in 10 auctions each. Cluster-robust standard errors are reported in parentheses. For all results: both within- and between- $\mathrm{R}^{2}$ are close to the overall $\mathrm{R}^{2}$. Significance niveaus are reported by stars: ***: $1 \%, * *: 5 \%, *: 10 \%$.

effects estimator we have to restrict our sample to bidders which are observed in at least two auctions. This leaves us with a sample of 941 bidders, taking part in 1,498 auctions from job category "painting" (the mean number of auction participations is 10, the median number is 6 ). In $22.2 \%$ of these auctions a bidder with a ratings difference of at least 90 takes part.

Table 4 shows our estimation results. The first column displays our base specification. In column two we add dummies to control for auction size and for regional influences. ${ }^{21}$ The

\footnotetext{
${ }^{21}$ We define auctions to be from the same region when the first digit of their zip code is identical.
} 
coefficients on the cost factors do not vary much between the specifications, and they are of reasonable size: A professional tradesman in Germany charges on average $€ 5-6$ per painted square meter. This includes painting, paint, cleaning and travel. The average area to be painted in the subset of auctions for which we have cost information available is $138.3 \mathrm{~m}^{2}$, the average travel distance $45.0 \mathrm{~km}$ (one-way). Together with our estimation results in table 4, this implies that the average price per square meter painted, including paint and travel, is about $€ 3-4$. Given that most of the bidders on the platform are non-professionals, ${ }^{22}$ this number seems to be plausible. In both specifications the coefficient on the strong rival indicator $S_{n j}$ is highly significant and strongly negative, meaning that bidders bid more competitive if they encounter a strong rival: they lower their bids by around $€ 90$, which is a quite strong reduction given that the average bid amount in our sample is around $€ 550$.

- Discussion of estimation results. Our estimation results show that bidders react to the appearance of a strong rival by lowering their bids. This verifies our assumption that bidders behave according to our information case model. However, as mentioned during the derivation of equation (11) above, the coefficient at the strong rival indicator $S_{n j}, \beta$, can only be interpreted as the direct causal effect of the appearance of a strong rival on bidder $j$ 's bidding behavior if the unobserved part of equation (11), $\nu_{n j}$, is mean independent from the observables $\mathbf{K}_{n j}$ and $S_{n j}$. In the following we shortly discuss why we are confident that mean independence holds.

$\nu_{n j}$ captures two unobserved influences on bidder $j$ 's bid: One stems from the composition of auction $n$ in terms of the qualities of bidder $j$ 's rivals, the other stems from bidder $j$ 's cost components. Thus, we have to ensure that our results are not biased by selection effects or the systematic omission of unobserved cost factors. With regard to selection effects, it might be that either strong bidders select themselves into certain auctions, or that certain types of bidders select themselves into auctions where a strong bidder is present. In effect, that would lead to a correlation between the appearance of a strong bidder and the

\footnotetext{
${ }^{22} 78 \%$ of the bidders in our sample are neither master craftsmen nor senior journeymen.
} 
composition of an auction in terms of bidders' qualities. To be sure that we actually capture the bidder's reaction to the appearance of a strong rival, in column 3 of table 4 we control for auction composition. We do so by taking the averages over the attributes of all "weak" bidders (bidders with a difference of positive and negative ratings of less than 90), and using these averages as further controls in our fixed effects regression. Controlling for the auction composition does not change our results.

Omission of unobserved cost factors is only problematic if these factors are systematically connected to the appearance of a strong rival. However, we do not think that the appearance of a strong rival is correlated with unobserved cost factors for two reasons: First, we collected our data by extracting cost information from the job offers as they were available to the bidders. It is quite unlikely that we systematically missed a factor which is observable to the bidders and which indicates a deviation in cost. Second, even if we missed a factor of this kind, it should be known to the buyers. Before an auction starts, the buyers announce a startprice. This startprice is announced for informational purposes, and it should be reasonable to assume that, when setting the startprices, besides at strategic considerations buyers orientate themselves at the costs of the job they offer. So, if there is a cost factor which is unobserved by us as researchers but known to the buyers and bidders, this cost factor should be reflected in the level of the startprice. Auctions in which a strong rival appears actually do systematically differ from auctions in which there is no strong rival in terms of the startprice. However, auctions in which a strong rival appears do not have a lower but a higher startprice, indicating that strong rivals select themselves into auctions which seem to be quite valuable relative to the observable cost elements. This kind of selection should work against the hypothetical effect of the appearance of a strong rival in the case of informed bidders. As we are still able to observe more competitive bidding when a strong rival appears, we are quite certain that the coefficient on $S_{n j}$ identifies strategic bidding behavior. 


\section{Counterfactual Analysis}

In this section we determine the impact of availability of quality information on the aggregate welfare of the buyers. In our data, information about bidders' non-price characteristics is publicly available, and bidders can infer information about the preferences of the buyers regarding their non-price characteristics from observing buyers' former decisions. Thus, bidders' behavior should be in line with the information case model we developed in section 2 . In section 5 we verified this assumption.

We are interested in how buyers' welfare would change in case non-price information was concealed from the bidders. That is, we are interested in a counterfactual scenario where bidders are informed about each other's prices but not about each other's non-price characteristics. The buyers on the other hand shall always be informed about all bidders' prices and non-price characteristics.

In order to calculate the change in buyers' welfare if quality information was concealed, we need information about bidders' counterfactual prices. With information about bidders' $\operatorname{cost} c_{n j}$ we could calculate these counterfactual prices by employing our no information case model. From our data we do not have explicit cost information, ${ }^{23}$ but as observed bidders' behavior is in line with our model for the case of disclosed quality information, we can use this model to derive estimates of each bidders' cost $c_{n j}$ from the observed prices $p_{n j}$.

Our counterfactual analysis proceeds as follows: In our data we have information about bidders' prices and bidders' non-price characteristics. We use this information together with the information on buyers' preferences from section 4 to solve our information case model (3) after estimates of bidders' costs $\hat{c}_{n j}$. We then use these cost estimates as input and solve our no information case model (6) after estimates of bidders' counterfactual prices $\hat{p}_{n j}$. Finally, we use our estimates of bidders' counterfactual prices $\hat{p}_{n j}$ to compute how buyers' welfare would change in case non-price information was concealed from the bidders. Figure 4 depicts

\footnotetext{
${ }^{23}$ Note that it is possible to extract information about common cost factors in auction $n$ from the job description (as we manually did for some auctions from category painting). However, for our counterfactual analysis we need information on the specific cost $c_{n j}$ bidder $j$ incurs in auction $n$.
} 


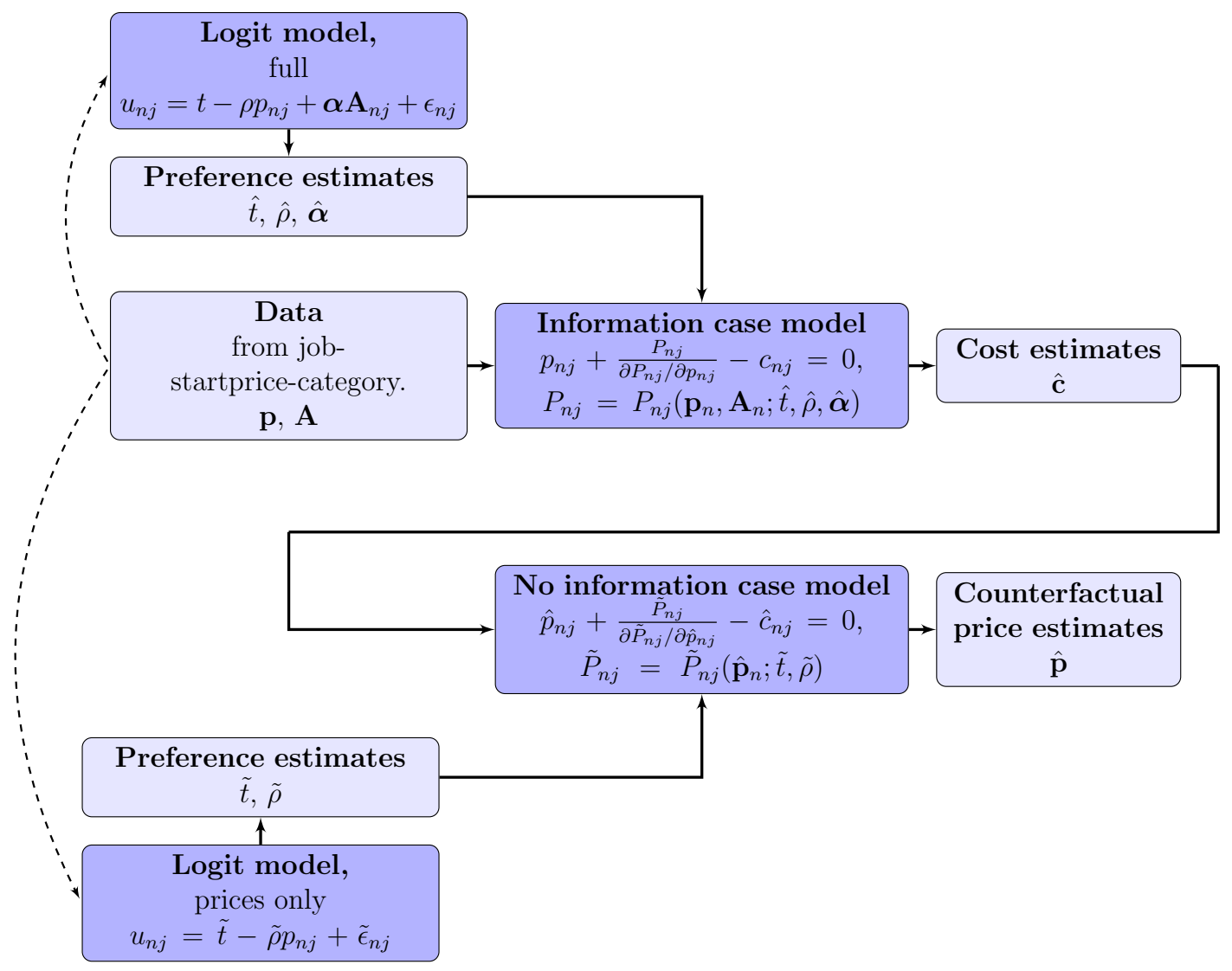

Figure 4: Sketch of the course of the counterfactual analysis.

the course of our counterfactual analysis schematically.

- Estimation of bidders' cost. Our assumption that bidders' behavior can be described by our model for the information case implies that the observed bids $p_{n j}$ are equilibrium bids which for every auction $n$ solve the bidders' first order conditions

$$
p_{n j}+\frac{P_{n j}}{\partial P_{n j} / \partial p_{n j}}-c_{n j}=0, \quad \forall j \in\left\{1, \ldots, J_{n}\right\} .
$$

Besides on bid amounts $p_{n j}$ and bidders non-price characteristics $\mathbf{A}_{n j}$, which we observe in our data, the winning probabilities $P_{n j}$ depend on the preferences $\{\rho, \boldsymbol{\alpha}\}$ of the buyer. By inserting our estimates $\{\hat{\rho}, \hat{\boldsymbol{\alpha}}\}$ from section 4 , we directly arrive at estimates $\hat{P}_{n j}$ for the 


\begin{tabular}{|c|c|c|c|c|c|c|}
\hline & Mean & $S D$ & Median & Mean & $S D$ & Median \\
\hline & \multicolumn{3}{|c|}{ Moving } & \multicolumn{3}{|c|}{ Painting } \\
\hline Actual bidamounts $\left(p_{n j}\right)$ & $€ 206.56$ & $€ 80.86$ & $€ 195$ & $€ 219.38$ & $€ 80.09$ & $€ 200$ \\
\hline Estimated costs $\left(\hat{c}_{n j}\right)$ & $\begin{array}{l}€ 134.41 \\
(€ 3.62)\end{array}$ & $€ 86.52$ & $€ 120.85$ & $\begin{array}{l}€ 155.53 \\
(€ 3.30)\end{array}$ & $€ 84.76$ & $€ 136.21$ \\
\hline \multirow[t]{2}{*}{$\begin{array}{l}\text { Counterfactual } \\
\text { bidamounts }\left(\hat{p}_{n j}\right)\end{array}$} & $\begin{array}{l}€ 208.69 \\
(€ 1.86)\end{array}$ & $€ 80.27$ & $€ 195.59$ & $\begin{array}{c}€ 224.81 \\
(€ 1.44)\end{array}$ & $€ 79.82$ & $€ 205.07$ \\
\hline & \multicolumn{3}{|c|}{ Car } & & & \\
\hline Actual bidamounts $\left(p_{n j}\right)$ & $€ 186.31$ & $€ 69.27$ & $€ 180$ & & & \\
\hline Estimated costs $\left(\hat{c}_{n j}\right)$ & $\begin{array}{c}€ 107.26 \\
(€ 9.02)\end{array}$ & $€ 74.49$ & $€ 97.10$ & & & \\
\hline $\begin{array}{l}\text { Counterfactual } \\
\text { bidamounts }\left(\hat{p}_{n j}\right)\end{array}$ & $\begin{array}{l}€ 187.72 \\
(€ 2.55)\end{array}$ & $€ 67.85$ & $€ 177.70$ & & & \\
\hline
\end{tabular}

Table 5: Estimated costs and counterfactual bidamounts for startprice-category 2 and all jobcategories. Displayed are summary statistics for actual bidamounts, estimated costs and estimated counterfactual bidamounts for all three job categories and for startprice-category 2 (which includes startprices from $€ 101-200$ ). The results are based on 2,418 auctions for job category "moving", on 1,509 auctions for job category "painting", and on 700 auctions for job category "car". Bootstrapped standard errors are given in parentheses.

winning probabilities:

$$
\hat{P}_{n j}= \begin{cases}\frac{1}{1+\sum_{k=1}^{J_{n}} e^{t+\hat{\rho} p_{n k}+\hat{\alpha} \mathbf{A}_{n k}}} & \text { if } j=0, \\ \frac{e^{t+\hat{\rho} p_{n j}+\hat{\alpha} \mathbf{A}_{n j}}}{1+\sum_{k=1}^{J_{n}} e^{t+\hat{\rho} p_{n k}+\hat{\alpha} \mathbf{A}_{n k}}} & \text { if } j \in\left\{1, \ldots, J_{n}\right\} .\end{cases}
$$

With these, the first order conditions (12) can be solved for estimates $\widehat{c}_{n j}$ of bidders' costs $c_{n j}$

Table 5 displays summary statistics of our cost estimates for startprice-category 2 and all three job-categories. To account for the fact that our cost estimates are based on estimates of the buyers' preferences, we computed bootstrapped standard errors. The standard error of the mean of our cost estimates ranges from $€ 4-9$. Thus, the estimates of bidders' costs are quite precise. The cost estimates become more meaningful if we look at the markup bidders 
Moving

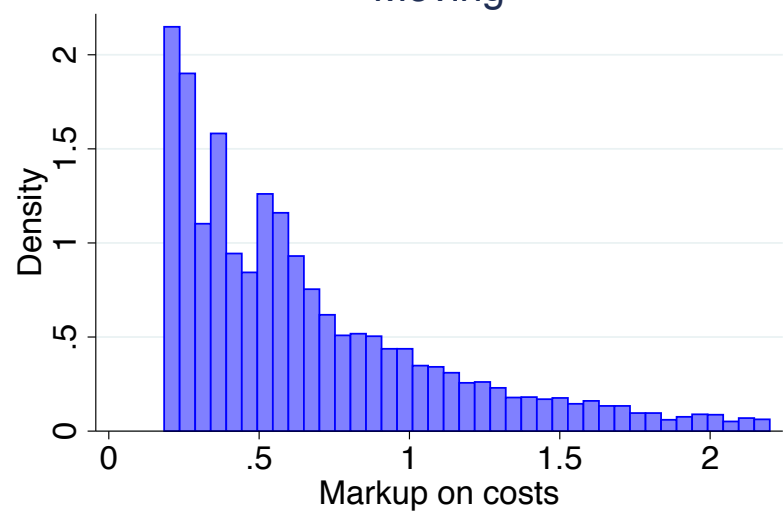

Car

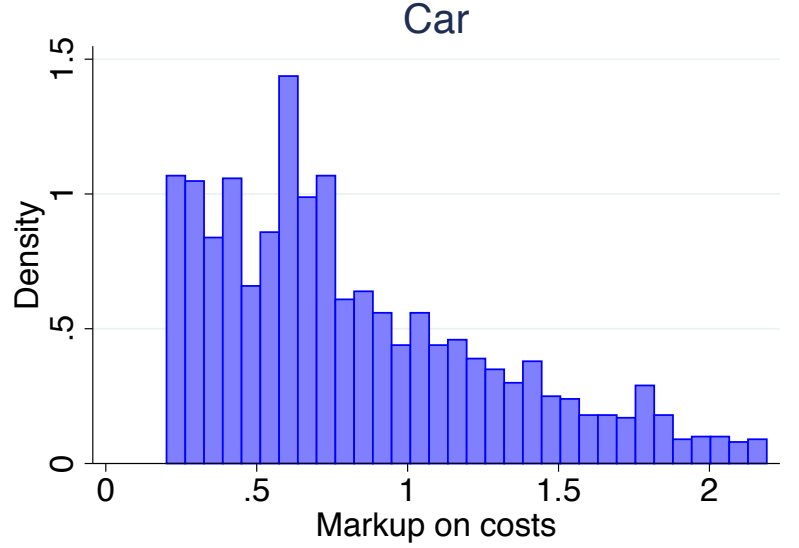

Painting

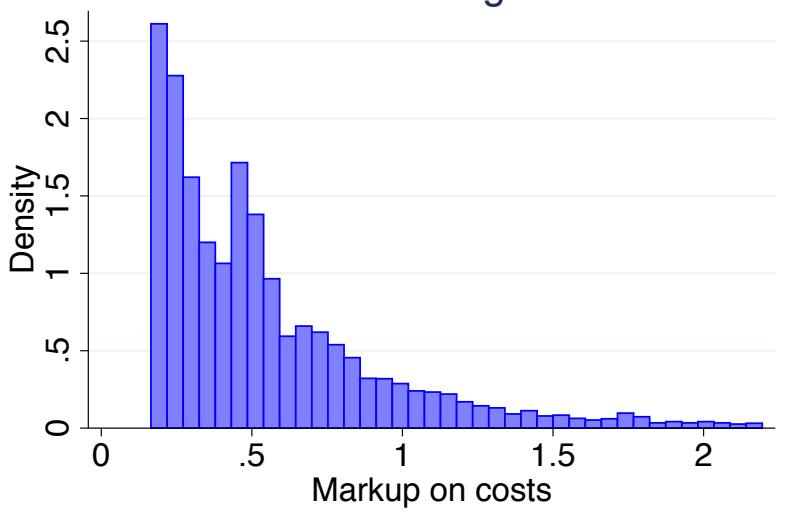

Figure 5: Distribution of bidders' markups. Displayed is the density distribution of bidders' markups on their (estimated) costs for all three job categories and startprice-category 2 (which includes startprices from $€ 101-200)$.

demand on their costs. Figure 5 displays the estimated distribution of bidders' markups on their costs for startprice-category 2 and all three job-categories. ${ }^{24}$ The median markup in the "painting" category is $46 \%$, in the "moving" category it is $59 \%$, and in the "car repairs" category it is $77 \%$.

Now, are these markups of a sensible order of magnitude? From the cost information we manually collected for a part of the auctions from category "painting" we know that for auctions from startprice-category 2 the average area to paint equals around $80 \mathrm{~m}^{2}$. In more illustrative terms, that for example could mean painting the walls and the ceilings of two

\footnotetext{
${ }^{24}$ Due to the sensitivity of our cost estimation to extreme bidamounts, for up to $5 \%$ of the bidders we get cost estimates close to zero and thus in turn quite high markups. For the sake of illustration these are omitted in figure 5 .
} 
small rooms of around $16 \mathrm{~m}^{2}$ floor space each. We assume that, depending on the level of practice, a job like this could be done by one person in around six hours. Startprice-category 2 includes auctions with startprices ranging from $€ 101-200$, and the level of bidders' prices is highly correlated with the level of the startprice. (Most of the auctions in this category have a startprice of $€ 200$.) Given a markup of $46 \%$, this roughly amounts to an hourly profit of around $€ 10$, which seems to be sensible.

- Counterfactual Simulation. Our counterfactual assumption is that non-price information is concealed from the bidders. In this case, the bidders' model of the buyers' decision process in a given auction $n$ is

$$
\begin{aligned}
\max _{j \in\left\{0,1, \ldots, J_{n}\right\}} & u_{n j}, \text { where } \\
u_{n 0} & =\tilde{\epsilon}_{n 0}, \\
u_{n j} & =\tilde{t}-\tilde{\rho} p_{n j}+\tilde{\epsilon}_{n j} \quad \text { for } j \in\left\{1, \ldots, J_{n}\right\} .
\end{aligned}
$$

Like in the information case, also in the no information case we assume that bidders gather information about the buyers' decision process by observing past auctions. We can put ourselves in the bidders' position in the counterfactual no information case by ignoring the non-price information available to us as econometricians and estimating choice model (15) only using price information. With our estimates $\tilde{t}$ and $\tilde{\rho}$ we can then formulate the bidders' first order conditions in the no information case as

$$
\hat{p}_{n j}+\frac{\tilde{P}_{n j}}{\partial \tilde{P}_{n j} / \partial \hat{p}_{n j}}-\hat{c}_{n j}=0, \quad j \in\left\{1, \ldots, J_{n}\right\}
$$

where

$$
\tilde{P}_{n j}=\frac{e^{\tilde{t}+\tilde{\rho} \hat{p}_{n j}}}{1+\sum_{k=1}^{J_{n}} e^{\tilde{+}+\tilde{\rho} \hat{p}_{n k}}} .
$$

We solve conditions (16) numerically for estimates $\hat{p}_{n j}$ of bidders' equilibrium prices in the no information case. 
With estimates $\hat{p}_{n j}$ of the counterfactual bids we can calculate the counterfactual aggregate utility of the buyers: Following Small and Rosen (1981), for type I extreme value distributed error terms $\epsilon_{j}$ the change in expected utility of the buyer in an auction $n$ can be calculated as

$$
\Delta \mathrm{EU}_{n}=\mathrm{EU}_{n}-\widetilde{\mathrm{EU}}_{n}=\ln \left(1+\sum_{j=1}^{J_{n}} e^{\hat{t}+\hat{\rho} p_{n j}+\hat{\boldsymbol{\alpha}} \mathbf{A}_{n j}}\right)-\ln \left(1+\sum_{j=1}^{J_{n}} e^{\hat{t}+\hat{\rho} \hat{p}_{n j}+\hat{\mathbf{\alpha}} \mathbf{A}_{n j}}\right) .
$$

The change in buyers' aggregate utility if quality information was concealed is then simply given as

$$
\Delta \mathrm{EU}_{\text {total }}=\sum_{n=1}^{N} \Delta \mathrm{EU}_{n}
$$

Division by $\hat{\rho}$ delivers the monetary equivalents of the changes in utility.

- Results. For each job-startprice category considered, we derive counterfactual estimates of prices, probabilities of unclosed deals, the aggregate welfare of the buyers, and the turnover created in all auctions in this job-startprice category. Tables 6 and 7 report our results. ${ }^{25}$ All our counterfactual results are based on estimates of the preferences of the buyers. To account for errors in these first step estimations we computed bootstrapped standard errors.

Table 6 shows that in case non-price information gets concealed we expect bidders' prices to increase significantly in categories "painting" and "moving". These results are in line with intuition: In categories "painting" and "moving", buyers' decisions are mainly influenced by bidders' prices and not so much their qualities (see table 2). In case information about bidders' quality gets concealed, the advantage of low-cost bidders is no longer mitigated by quality information (the assumption here is that low quality correlates with low costs). Thus, competitive pressure decreases and prices increase. In category "car repairs", where quality information strongly influences buyers' decisions (see table 2), prices do not change

\footnotetext{
${ }^{25} \mathrm{~A}$ more detailed overview of all our results is given in tables 8 and 9 in the appendix.
} 
Changes in mean bidamount:

\begin{tabular}{l|ccc}
$\begin{array}{l}\text { Startprice- } \\
\text { category }\end{array}$ & Moving & $\begin{array}{c}\text { Job-category } \\
\text { Painting }\end{array}$ & Car \\
\hline 2 & $1.0 \%^{* * *}$ & $2.5 \%^{* * *}$ & $0.8 \%$ \\
$(€ 101-200)$ & $(0.4 \%, 2,418$ auct. $)$ & $(0.4 \%, 1,509$ auct. $)$ & $(1.0 \%, 700$ auct. $)$ \\
3 & & & \\
$(€ 201-300)$ & $1.5 \%^{* * *}$ & $3.0 \%^{* * *}$ & $0.5 \%$ \\
5 & $(0.3 \%, 1,692$ auct. $)$ & $(0.5 \%, 1,578$ auct. $)$ & $(1.4 \%, 480$ auct. $)$ \\
$(€ 401-500)$ & $(0.5 \%, 1,446$ auct. $)$ & $(0.8 \%, 1,312$ auct. $)$ & $(7.3 \%, 229$ auct. $)$ \\
& & & \\
\hline
\end{tabular}

Changes in probability of an unclosed deal:

\begin{tabular}{l|ccc}
$\begin{array}{l}\text { Startprice- } \\
\text { category }\end{array}$ & Moving & $\begin{array}{c}\text { Job-category } \\
\text { Painting }\end{array}$ & Car \\
\hline 2 & $0.3 \%$ & $3.9 \%^{* *}$ & $-0.6 \%$ \\
$(€ 101-200)$ & $(1.0 \%, 2,418$ auct. $)$ & $(1.6 \%, 1,509$ auct. $)$ & $(3.6 \%, 700$ auct. $)$ \\
3 & & & \\
$(€ 201-300)$ & $1.6 \%^{*}$ & $5.8 \%^{* * *}$ & $-10.9 \%^{* *}$ \\
5 & $(0.9 \%, 1,692$ auct. $)$ & $(1.4 \%, 1,578$ auct. $)$ & $(4.5 \%, 480$ auct. $)$ \\
$(€ 401-500)$ & $4.2 \%^{* * *}$ & $7.3 \%^{* * *}$ & $1.4 \%$ \\
& $(1.4 \%, 1,446$ auct. $)$ & $(1.7 \%, 1,312$ auct. $)$ & $(9.8 \%, 229$ auct. $)$ \\
\hline
\end{tabular}

Table 6: Estimated changes in mean bidamount and the probability of an unclosed deal. For all job-startprice categories considered, the tables display the expected changes in bidders' mean bidamount and in the probability of an unclosed deal in case non-price information gets concealed. All auctions were conducted during the second half of 2008. The number of auctions and bootstrapped standard errors are given in parentheses. Significance niveaus are reported by stars: ***: $1 \%, * *: 5 \%, *: 10 \%$.

significantly. The reason is that in case non-price information gets concealed, bidders are no longer aware of their relative strength respectively weakness with respect to their quality. This leads to lower prices of high-quality bidders, and higher prices of low-quality bidders. Due to this opposite development the average price does not change significantly.

In categories "painting" and "moving" in case non-price information gets concealed the outside option is likely to be chosen more often. The reason is that with increasing prices the outside option becomes more attractive to buyers. In contrast, in category "car repairs" there is a pronounced decrease in the probability of unclosed deals. As just mentioned, 
Changes in buyers' aggregate welfare

\begin{tabular}{l|ccc}
$\begin{array}{l}\text { Startprice- } \\
\text { category }\end{array}$ & Moving & $\begin{array}{c}\text { Job-category } \\
\text { Painting }\end{array}$ & Car \\
\hline 2 & $-0.3 \%$ & $-3.2 \%^{* *}$ & $0.6 \%$ \\
$(€ 101-200)$ & $(1.0 \%, 2,418$ auct. $)$ & $(1.3 \%, 1,509$ auct. $)$ & $(4.9 \%, 700$ auct. $)$ \\
3 & & & \\
$(€ 201-300)$ & $(0.6 \%, 1,692$ auct. $)$ & $(0.9 \%, 1,578$ auct. $)$ & $(6.4 \%, 480$ auct. $)$ \\
5 & & & $14.7 \% * *$ \\
$(€ 401-500)$ & $(1.0 \%, 1,446$ auct. $)$ & $(1.5 \%, 1,312$ auct. $)$ & $(33.3 \%, 229$ auct. $)$ \\
& & & \\
\hline
\end{tabular}

Changes in platform turnover

\begin{tabular}{l|ccc}
$\begin{array}{l}\text { Startprice- } \\
\text { category }\end{array}$ & Moving & $\begin{array}{c}\text { Job-category } \\
\text { Painting }\end{array}$ & Car \\
\hline 2 & $1.0 \%$ & $-1.3 \%$ & $1.1 \%$ \\
$(€ 101-200)$ & $(1.0 \%, 2,418$ auct. $)$ & $(1.6 \%, 1,509$ auct. $)$ & $(4.9 \%, 700$ auct. $)$ \\
3 & & & \\
$(€ 201-300)$ & $(0.9 \%, 1,692$ auct. $)$ & $(1.1 \%, 1,578$ auct. $)$ & $(6.0 \%, 480$ auct. $)$ \\
5 & $-1.3 \%$ & $-1.4 \%$ & $-4.4 \%$ \\
$(€ 401-500)$ & $(1.2 \%, 1,446$ auct. $)$ & $(1.5 \%, 1,312$ auct. $)$ & $(19.7 \%, 229$ auct. $)$ \\
& & & \\
\hline
\end{tabular}

Table 7: Estimated changes in buyers' aggregate welfare and platform turnover in case nonprice information gets concealed from the bidders. For all job-startprice categories considered, the tables display the expected changes in buyers' welfare and in platform turnover in case non-price information gets concealed. The percentage changes in welfare were derived by computing the monetary equivalent of the total change of buyers' welfare and then relating it to total auction turnover in the job-startprice-category considered. All auctions were conducted during the second half of 2008 . The number of auctions and bootstrapped standard errors are given in parentheses. Significance niveaus are reported by stars: ***: 1\%, **: $5 \%, *: 10 \%$.

concealment of non-price information leads to lower prices of high-quality bidders, and higher prices of low-quality bidders. Thus, high-quality bidders become "cheaper" for the buyers, which renders the outside option relatively less attractive. Therefore the relative number of auctions in which deals remain unclosed drops.

Our results so far show that in categories where the influence of bidders' non-price characteristics on buyers' decisions are weak ("painting" and "moving"), concealment of non-price information leads to an increase in average prices and a decrease in the rate of successfully 
closed deals. In categories where bidders' non-price characteristics are of quite strong influenced on buyers' decisions ("car repairs"), concealment of non-price information decreases prices of high-quality bidders, which in turn fosters deals between buyers and bidders. Accordingly, as shown in table 7, when non-price information is concealed buyers' aggregate welfare in categories painting and moving decreases, whereas it increases in category "car repair" ${ }^{26}$

The online auction platform on which the auctions in our sample are conducted charges a certain percentage of the price to which a deal is closed between a bidder and a buyer as commission. That is, the earnings of the platform increase with the turnover created in the auctions. The effect of concealment of non-price information on auction turnover is ambiguous: In categories where bidders' non-price characteristics are only of small influence on buyers' decisions ("painting" and "moving"), concealment of non-price information increases prices but decreases the rate of successfully closed deals. In categories where bidders' non-price characteristics strongly influence buyers' decisions ("car repairs"), concealment of non-price information increases the rate of successfully closed deals but decreases the prices of high-quality bidders. The results displayed in table 7 show that for categories "painting" and "moving", where bidders' non-price characteristics are only of small influence on buyers' decisions, the effect of a decrease in the rate of successfully seems to be balanced by that of an increase in prices. For category "car repairs" where bidders' non-price characteristics are of high importance for buyers' decisions, the increase in the rate of successfully closed deals outweighs the decrease in high-quality bidders' prices, and turnover thus drops by up to $13 \%$.

Robustness of our counterfactual results. The results of our counterfactual simulation are only meaningful if - although necessarily stylized - our theoretical framework captures the fundamental mechanics of the application at hand sufficiently well. Our frame-

\footnotetext{
${ }^{26}$ The welfare changes displayed in table 7 are expressed in percentages of total revenues made (in monetary terms) in the respective category during the observation period. Total revenues range from around $€ 360,000$ in job-category "moving", startprice-category 5 , to around $€ 34,000$ in job-category "car", startprice-category 5 .
} 
work abstracts from inter-auction dynamics, sniping and selection issues. In the following, we discuss why neglecting these factors is justified for our application respectively how taking them into account might alter our results.

We abstract from inter-auction dynamics, which means that we assume both buyers and bidders not to behave strategically across auctions. We think this assumption is reasonable for our application for two reasons: First, as during the time period considered each buyer on average auctions off only one contract, we can exclude strategic inter-auction behavior of buyers. Second, the probability of repeated encounters between bidders is quite low: On average, a given bidder encounters only $12 \%$ of his rivals at least twice. Thus, it should be reasonable to assume that, if at all, phenomenons like tacit collusion play a negligible role. We also do not think that explicit collusion in a given auction plays a role: For once, bidders are not able to communicate with each other on the online platform. Then, as shown on the map in figure 3, most auctions are procuring jobs in large cities respectively metropolitan areas. There, in contrast to rural areas, bidders should not know about the whole pool of potential rivals, what makes interactions between them apart from that on the platform unlikely.

A related but slightly different concern might be that some bidders behave strategically across auctions due to capacity constraints, like in for example Jofre-Bonet and Pesendorfer (2000). However, the auctions we consider are about smaller jobs which should take about one to at most three days to complete, and in the time span we consider (half a year) the average number of auction participations is around four. Thus, we do not think that capacity constraints do play a major role here. To summarize, we think that modeling each auction in an isolated manner is a reasonable approach for our application.

We further made the assumption that a bidding equilibrium emerges in each auction. In particular, this assumption implies that dynamic phenomenons like sniping do not occur in our application. Given the numbers in table 1 this assumption seems to be justified: On average, the last bid is placed well before the end of an auction, meaning that sniping seems 
to play no role in our data. Thus, the assumption that in each auction in our application an equilibrium is achieved should be justified.

A more critical assumption implicit in our model is that a change in the information structure does not affect the composition of auction participants. It might be that in categories where bidders' non-price characteristics are of low importance for the buyers' decisions the increase in prices due to concealed non-price information attracts additional bidders. This would intensify competition, which in turn would force prices down again. Similarly, in categories where bidders' non-price characteristics are of high importance to buyers' decisions, intensified price competition due to concealed non-price information might lead to bidders dropping out of auctions. Both these changes in auction composition would work against the results we presented above. However, we do not expect the effects of changes in auction compositions due to concealment of non-price information to be large. The reason is that auction participation is rather costless for bidders - after they paid the "fixed cost" of registering at the auction platform, auction participation is just a matter of a few clicks - that is, a bidder's (variable) cost from participating at an auction should be negligible relative to his expected utility from participation both in case non-price information is public and in case non-price information is concealed. Thus, we do not expect auction compositions to change significantly in case non-price information gets concealed.

\section{Conclusion}

Non-binding reverse auctions are establishing as one of the most prominent tools for electronic procurement activities both of firms and government organizations. Whereas in non-binding auctions typically no structure is imposed on the buyer's decision process, important design questions arise, however, with respect to the information regime throughout the bidding process. We added to the understanding of this auction format by analyzing the effects of different designs of the information structure of an open non-binding auction. In 
particular, under the assumption that prices are always visible, we examined what effects disclosure respectively concealment of information about bidders' non-price characteristics has on the aggregate welfare of the buyers.

After establishing a formal framework, we first observed that buyers prefer that informational arrangement which creates higher competitive pressure among bidders. As we showed, which of the informational regimes indeed induces more competitive pressure crucially depends on the precise situation considered. Thus, from a theory point of view none of the regimes dominates.

To obtain further insights on the impact of the information regimes in non-binding auctions for real market situations, we then conducted an empirical analysis based on an extensive data set from a large European online procurement platform. The informational setup on this platform is such that bidders are informed about each other's non-price characteristics. Building on our formal framework, we performed a counterfactual welfare analysis to assess the consequences of concealing non-price information from the bidders. We find that our theoretical result - that the effect of concealment of non-price information depends on how strong buyers weigh bidders' non-price characteristics - is of economic significance for applications in the field. For auction categories where bidders non-price characteristics are of high importance for the decisions of the buyers, in case non-price information was concealed we would expect buyers' welfare to increase by up to $15 \%$. Also, we would expect turnover to increase by up to $13 \%$. In contrast, for auction categories where bidders non-price characteristics are of low importance for the decisions of the buyers, in case non-price information was concealed we would expect buyers' welfare to decrease by up to $6 \%$ and turnover to decrease by up to $2 \%$. The latter is the case in the by far most popular job-category on the platform.

The final policy recommendation implied by those results clearly depends very much on the final objectives of the online platform. Especially for business models in the very dynamic online markets, often rapid growth is much more important than instantaneous 
profits. In a recent interview for HBR IdeaCast from Harvard Business Review, Jeff Bezos, CEO of Amazon.com, for example states: "Percentage margins are not one of the things we are seeking to optimize. It's the absolute dollar-free cash flow per share that you want to maximize, [...]" And later on: "[W]e believe by keeping our prices very, very low, we earn trust with customers over time, and that actually does maximize free cash flow over the long term." 27 A formal consideration of the dynamic aspects such as the long run profitability of firm growth in a specific sector by far exceeds the bounds of our structural analysis. Nevertheless, our analysis can contribute to questions arising in this broader context. If the most challenging task to achieve the long run growth objectives of the online platform indeed is to attract as many buyers as possible (even at the expense of smaller short-run profits), then our results clearly show that the current information regime to reveal all non-price information is the one to best implement this objective, as it maximizes buyers' welfare in the most popular auction categories.

\footnotetext{
${ }^{27}$ Source: Interview with Jeff Bezos, HBR IdeaCast from Harvard Business Review, January 3, 2013.
} 


\section{References}

Asker, J. and E. Cantillon (2008). Properties of scoring auctions. RAND Journal of Economics 39, 69-85.

Asker, J. and E. Cantillon (2010). Procurement when price and quality matter. RAND Journal of Economics 41, 1-34.

Athey, S. and J. Levin (2001). Information and competition in U.S. Forest Service timber auctions. Journal of Political Economy 109, 375-417.

Bichler, M. and J. Kalagnanam (2005). Configurable offers and winner determination in multi-attribute auctions. European Journal of Operations Research 160, 380-394.

Branco, F. (1997). The design of multidimensional auctions. RAND Journal of Economics 28, 63-81.

Brosig-Koch, J. and T. Heinrich (2014). Reputation and mechanism choice in procurement auctions: An experiment. Production and Operations Management Society, forthcoming.

Caplin, A. and B. Nalebuff (1991). Aggregation and imperfect competition: on the existence of equilibrium. Econometrica 59, 25-59.

Che, Y.-K. (1993). Design competition through multidimensional auctions. RAND Journal of Economics 24, 668-680.

Chen-Ritzo, C.-H., T. P. Harrison, A. M. Kwasnica, and D. J. Thomas (2005). Better, faster, cheaper: An experimental analysis of a multiattribute reverse auction mechanism with restricted information feedback. Management Science 51, 1753-1762.

Colucci, D., N. Doni, and V. Valori (2011). Information disclosure in procurement auctions with horizontally differentiated suppliers. Working Paper. 
Doni, N. and D. Menicucci (2010). A note on informational disclosure in procurement auctions. Economics Letters 108, 307-310.

Engelbrecht-Wiggans, R., E. Haruvy, and E. Katok (2007). A comparison of buyerdetermined and price-based multiattribute mechanisms. Marketing Science 26, 629-641.

Fugger, N., E. Katok, and A. Wambach (2013). Collusion in dynamic buyer-determined reverse auctions. Working Paper.

Gal-Or, E., M. Gal-Or, and A. Dukes (2007). Optimal information revelation in procurement schemes. RAND Journal of Economics 38, 400-418.

Haruvy, E. and E. Katok (2013). Increasing revenue by decreasing information in procurement auctions. Production and Operations Management 22, 19-35.

Jap, S. D. (2002). Online reverse auctions: Issues, themes and prospects for the future. Journal of the Academy of Marketing Science 30, 506-525.

Jap, S. D. (2003). An exploratory study of the introduction of online reverse auctions. Journal of Marketing 67, 96-107.

Jap, S. D. and E. Haruvy (2008). Interorganizational relationships and bidding behavior in industrial online reverse auctions. Journal of Marketing Research 45, 550-561.

Jofre-Bonet, M. and M. Pesendorfer (2000). Bidding behavior in a repeated procurement auction: A summary. European Economic Review 44, 1006-1020.

Kostamis, D., D. R. Beil, and I. Duenyas (2009). Total-cost procurement auctions: Impact of suppliers' cost adjustments on auction format choice. Management Science 55, 1985-1999.

Lewis, G. and P. Bajari (2011). Procurement contracting with time incentives: Theory and evidence. The Quarterly Journal of Economics 126, 1173-1211. 
Mizuno, T. (2003). On the existence of a unique price equilibrium for models of product differentiation. International Journal of Industrial Organization 21, 761-793.

Nisan, N., M. Schapira, G. Valiant, and A. Zohar (2011). Best-response auctions. In Proceedings of the 12th ACM conference on Electronic commerce, pp. 351-360. ACM.

Parkes, D. and J. Kalagnanam (2005). Models of iterative multi-attribute vickrey auctions. Management Science 51, 435-451.

Rezende, L. (2009). Biased procurement auctions. Economic Theory 38, 169-185.

Small, K. A. and H. S. Rosen (1981). Welfare economics with discrete choice models. Econometrica 49, 105-130.

Sobel, M. and W. Wei (2010). Myopic solutions of homogeneous sequential decision processes. Operations Research 58, 1235-1246.

Wan, Z. and D. R. Beil (2012). Rfq auctions with supplier qualification screening. Operations Research 57, 934-949.

Wan, Z., D. R. Beil, and E. Katok (2012). When does it pay to delay supplier qualification? theory and experiments. Management Science 58, 2057-2075.

Weizsaecker, G. (2003). Ignoring the rationality of others: evidence from experimental normal-form games. Games and Economic Behavior 44, 145-171. 


\section{A Appendix}

\section{A.1 Illustration: No information structure dominates the other}

As the firms' first order conditions given in (3) and (6) are transcendental given any standard assumption about the distribution of the error terms $\epsilon_{i}$, it is impossible to derive closed form solutions for the equilibrium prices in both the information and the no information case. In order to demonstrate that no information structure weakly dominates the other we thus resort to the use of numerical simulations.

We look at an auction with two bidding firms. The cost of the firms are $\mathbf{c}=\left(c_{1}, c_{2}\right)=$ $(0,1)$. We make the assumption that the error terms $\epsilon_{i}$ are iid type I extreme value distributed, and that the distribution of quality $f\left(q_{j}\right)$ is discrete: $q_{1}$ shall be drawn with probability $0.1, q_{2}$ with probability 0.9 .

Then for $\mathbf{q}=\left(q_{1}, q_{2}\right)=(0,1)$ we get $\mathrm{EU}-\widetilde{\mathrm{EU}}=0.75$. Thus, for these parameter values the buyer prefers the information case over the no information case. In contrast, for $\mathbf{q}=(0,3)$ we get $\mathrm{EU}-\widetilde{\mathrm{EU}}=-0.34$. With these parameter values the buyer prefers the no information case over the information case.

\section{A.2 Derivation of analytical results}

We assume $\epsilon_{2}-\epsilon_{1}$ to follow a uniform distribution with mean zeor and variance $\nu$, and $\tilde{\epsilon}_{2}-\tilde{\epsilon}_{1}$ to follow a uniform distribution with mean zero and variance $\tilde{\nu}$. It holds that $\tilde{\nu} \geq \nu$. Accordingly, the cumulative distribution function of $\epsilon_{2}-\epsilon_{1}$ is given as

$$
F_{\epsilon_{2}-\epsilon_{1}}(x)= \begin{cases}0 & \text { for } x<-\sqrt{12 \nu} \\ \frac{1}{2}+\frac{1}{\sqrt{12 \nu}} x & \text { for }-\sqrt{12 \nu} \leq x<\sqrt{12 \nu} \\ 1 & \text { for } x \geq \sqrt{12 \nu}\end{cases}
$$

and that of $\tilde{\epsilon}_{2}-\tilde{\epsilon}_{1}$ as

$$
F_{\tilde{\epsilon}_{2}-\tilde{\epsilon}_{1}}(x)= \begin{cases}0 & \text { for } x<-\sqrt{12 \tilde{\nu}} \\ \frac{1}{2}+\frac{1}{\sqrt{12 \tilde{\nu}}} x & \text { for }-\sqrt{12 \tilde{\nu}} \leq x<\sqrt{12 \tilde{\nu}} \\ 1 & \text { for } x \geq \sqrt{12 \tilde{\nu}}\end{cases}
$$

For the sake of exposition in the following we focus on the parameter space for which we get interior solutions. That is the parameter space for which both $-\sqrt{12 \nu} \leq p_{2}^{*}-q_{2}-p_{1}^{*}-q_{1}<$ $\sqrt{12 \nu}$ and $-\sqrt{12 \tilde{\nu}} \leq \tilde{p}_{2}^{*}-\tilde{p}_{1}^{*}<\sqrt{12 \tilde{\nu}} . p_{i}^{*}$ and $\tilde{p}_{i}^{*}$ are the equilibrium prices in the information respectively the no information case. These conditions hold if $0 \leq c_{2}-c_{1}<3 \sqrt{12 \tilde{\nu}}$ and $-3 \sqrt{12 \nu}+\left(c_{2}-c_{1}\right)<q_{2}-q_{1} \leq 3 \sqrt{12 \nu}+\left(c_{2}-c_{1}\right)$. Note that for the parameter space depicted in figure 1 we get interior solutions. In the complementary parameter space the situation in at least one of the two information cases turns deterministic, as due to the limited support of $\epsilon_{2}-\epsilon_{1}$ respectively $\tilde{\epsilon}_{2}-\tilde{\epsilon}_{1}$ randomness in the error terms no longer has an effect on the buyer's decision (as perceived by the bidders). This alters the position of the buyer's indifference line but has no effect on our basic finding that for large cost differences 
and small quality differences the buyer prefers the information case, while for small cost differences and large quality differences he prefers the no information case.

The firms' winning probabilities in the information case are

$$
\begin{aligned}
& P_{1}(\mathbf{p}, \mathbf{q})=P\left(\epsilon_{2}-\epsilon_{1} \leq p_{2}-q_{2}-p_{1}+q_{1}\right)=F_{\epsilon_{2}-\epsilon_{1}}\left(p_{2}-q_{2}-p_{1}+q_{1}\right), \\
& P_{2}(\mathbf{p}, \mathbf{q})=P\left(\epsilon_{2}-\epsilon_{1}>p_{2}-q_{2}-p_{1}+q_{1}\right)=1-F_{\epsilon_{2}-\epsilon_{1}}\left(p_{2}-q_{2}-p_{1}+q_{1}\right) .
\end{aligned}
$$

If the $P_{j}$ in the first order conditions (3) are expressed using the approximation (A2), it is straightforward to solve these systems after the equilibrium prices $\mathbf{p}^{*}$ :

$$
\begin{aligned}
& p_{1}^{*}=\frac{1}{3}\left(2 c_{1}+c_{2}\right)-\frac{1}{3}\left(q_{2}-q_{1}\right)+\sqrt{3 \nu}, \\
& p_{2}^{*}=\frac{1}{3}\left(c_{1}+2 c_{2}\right)+\frac{1}{3}\left(q_{2}-q_{1}\right)+\sqrt{3 \nu} .
\end{aligned}
$$

The firms' winning probabilities in the no information case are

$$
\begin{aligned}
& \tilde{P}_{1}(\mathbf{p}, \mathbf{q})=P\left(\tilde{\epsilon}_{2}-\tilde{\epsilon}_{1} \leq \tilde{p}_{2}-\tilde{p}_{1}\right)=F_{\tilde{\epsilon}_{2}-\tilde{\epsilon}_{1}}\left(\tilde{p}_{2}-\tilde{p}_{1}\right), \\
& \tilde{P}_{2}(\mathbf{p}, \mathbf{q})=P\left(\tilde{\epsilon}_{2}-\tilde{\epsilon}_{1}>\tilde{p}_{2}-\tilde{p}_{1}\right)=1-F_{\tilde{\epsilon}_{2}-\tilde{\epsilon}_{1}}\left(\tilde{p}_{2}-\tilde{p}_{1}\right) .
\end{aligned}
$$

Using the first order conditions (6), it follows that the equilibrium prices in the no information case are given as

$$
\begin{aligned}
& \tilde{p}_{1}^{*}=\frac{1}{3}\left(2 c_{1}+c_{2}\right)+\sqrt{3 \tilde{\nu}} \\
& \tilde{p}_{2}^{*}=\frac{1}{3}\left(c_{1}+2 c_{2}\right)+\sqrt{3 \tilde{\nu}} .
\end{aligned}
$$

From simply comparing $\left(p_{1}^{*}, p_{2}^{*}\right)$ to $\left(\tilde{p}_{1}^{*}, \tilde{p}_{2}^{*}\right)$, it follows that

$$
\begin{aligned}
& p_{1}^{*}=\tilde{p}_{1}^{*}-\frac{1}{3}\left(q_{2}-q_{1}\right)-\sqrt{3}(\sqrt{\tilde{\nu}}-\sqrt{\nu}), \\
& p_{2}^{*}=\tilde{p}_{2}^{*}+\frac{1}{3}\left(q_{2}-q_{1}\right)-\sqrt{3}(\sqrt{\tilde{\nu}}-\sqrt{\nu}) .
\end{aligned}
$$

According to Small and Rosen (1981) the change in the buyer's expected utility from a change in the information structure can be computed as

$$
\Delta \mathrm{EU}=\mathrm{EU}-\widetilde{\mathrm{EU}}=\int_{\left(\widetilde{W_{1}}, \widetilde{W_{2}}\right)}^{\left(W_{1}, W_{2}\right)}\left\{P_{1}\left(W_{1}, W_{2}\right) \mathrm{d} W_{1}+\left[1-P_{1}\left(W_{1}, W_{2}\right)\right] \mathrm{d} W_{2}\right\},
$$

where $W_{1}=q_{1}-p_{1}, W_{2}=q_{2}-p_{2},\left(\widetilde{W_{1}}, \widetilde{W}_{2}\right)=\left(q_{1}-\tilde{p}_{1}^{*}, q_{2}-\tilde{p}_{2}^{*}\right),\left(W_{1}, W_{2}\right)=\left(q_{1}-p_{1}^{*}, q_{2}-p_{2}^{*}\right)$ 
and $P_{1}\left(W_{1}, W_{2}\right)=\frac{1}{2}+\sqrt{12 \nu}\left(W_{1}-W_{2}\right)$. Some algebra delivers

$$
\begin{aligned}
\mathrm{EU}-\widetilde{\mathrm{EU}}=\frac{1}{3 \sqrt{12 \nu}}\left(q_{2}-q_{1}\right)\left[\left(c_{2}-c_{1}\right)-2\left(q_{2}-q_{1}\right)\right] \\
+3(2 \sqrt{\nu \tilde{\nu}}+\tilde{\nu}-3 \nu) \\
\quad+\left(\frac{\sqrt{\tilde{\nu}}}{2 \sqrt{\nu}}-\frac{1}{2}\right)\left(c_{2}+c_{1}-q_{2}-q_{1}\right),
\end{aligned}
$$

as stated in the main body of the text. 


\section{A.3 Counterfactual estimates}

\begin{tabular}{|c|c|c|c|c|}
\hline \multirow{2}{*}{$\begin{array}{l}\text { Startprice- } \\
\text { category }\end{array}$} & & \multicolumn{3}{|c|}{ Job-category } \\
\hline & & Moving & Painting & Car \\
\hline \multirow[t]{4}{*}{$2(€ 101-200)$} & Mean bidamount & $\begin{array}{l}1.0 \% \\
(0.4 \%)\end{array}$ & $\begin{array}{l}2.5 \% \\
(0.4 \%)\end{array}$ & $\begin{array}{c}0.8 \% \\
(1.0 \%)\end{array}$ \\
\hline & Freq. outside option & $\begin{array}{c}0.3 \% \\
(1.0 \%)\end{array}$ & $\begin{array}{l}3.9 \% \\
(1.2 \%)\end{array}$ & $\begin{array}{l}-0.6 \% \\
(3.6 \%)\end{array}$ \\
\hline & Aggr. buyer welfare & $\begin{array}{l}-0.3 \% \\
(1.0 \%)\end{array}$ & $\begin{array}{l}-3.2 \% \\
(1.2 \%)\end{array}$ & $\begin{array}{l}0.6 \% \\
(4.9 \%)\end{array}$ \\
\hline & Platform turnover & $\begin{array}{l}1.0 \% \\
(1.0 \%)\end{array}$ & $\begin{array}{l}-1.3 \% \\
(1.4 \%)\end{array}$ & $\begin{array}{l}1.1 \% \\
(4.9 \%)\end{array}$ \\
\hline \multirow[t]{4}{*}{$\begin{array}{l}3 \\
(€ 201-300)\end{array}$} & Mean bidamount & $\begin{array}{l}1.5 \% \\
(0.3 \%)\end{array}$ & $\begin{array}{l}3.0 \% \\
(0.5 \%)\end{array}$ & $\begin{array}{c}0.5 \% \\
(1.4 \%)\end{array}$ \\
\hline & Freq. outside option & $\begin{array}{l}1.6 \% \\
(0.9 \%)\end{array}$ & $\begin{array}{l}5.8 \% \\
(1.2 \%)\end{array}$ & $\begin{array}{c}-10.9 \% \\
(4.5 \%)\end{array}$ \\
\hline & Aggr. buyer welfare & $\begin{array}{l}-1.3 \% \\
(0.6 \%)\end{array}$ & $\begin{array}{l}-4.0 \% \\
(0.9 \%)\end{array}$ & $\begin{array}{l}14.7 \% \\
(6.4 \%)\end{array}$ \\
\hline & Platform turnover & $\begin{array}{c}0.2 \% \\
(0.9 \%)\end{array}$ & $\begin{array}{l}-2.0 \% \\
(1.0 \%)\end{array}$ & $\begin{array}{l}13.3 \% \\
(6.0 \%)\end{array}$ \\
\hline \multirow[t]{4}{*}{$\begin{array}{l}4 \\
(€ 301-400)\end{array}$} & Mean bidamount & $\begin{array}{l}1.6 \% \\
(0.5 \%)\end{array}$ & $\begin{array}{l}4.2 \% \\
(0.6 \%)\end{array}$ & $\begin{array}{c}0.7 \% \\
(1.9 \%)\end{array}$ \\
\hline & Freq. outside option & $\begin{array}{l}1.0 \% \\
(1.5 \%)\end{array}$ & $\begin{array}{c}6.7 \% \\
(1.4 \%)\end{array}$ & $\begin{array}{l}3.6 \% \\
(4.7 \%)\end{array}$ \\
\hline & Aggr. buyer welfare & $\begin{array}{l}-0.7 \% \\
(1.1 \%)\end{array}$ & $\begin{array}{l}-3.9 \% \\
(0.9 \%)\end{array}$ & $\begin{array}{l}-3.3 \% \\
(5.4 \%)\end{array}$ \\
\hline & Platform turnover & $\begin{array}{c}0.3 \% \\
(1.3 \%)\end{array}$ & $\begin{array}{l}-1.1 \% \\
(1.2 \%)\end{array}$ & $\begin{array}{l}-6.4 \% \\
(6.5 \%)\end{array}$ \\
\hline \multirow[t]{4}{*}{$\begin{array}{l}5 \\
(€ 401-500)\end{array}$} & Mean bidamount & $\begin{array}{l}2.7 \% \\
(0.5 \%)\end{array}$ & $\begin{array}{c}5.2 \% \\
(0.8 \%)\end{array}$ & $\begin{array}{c}0.9 \% \\
(7.3 \%)\end{array}$ \\
\hline & Freq. outside option & $\begin{array}{l}4.2 \% \\
(1.4 \%)\end{array}$ & $\begin{array}{c}7.3 \% \\
(1.7 \%)\end{array}$ & $\begin{array}{l}1.4 \% \\
(9.8 \%)\end{array}$ \\
\hline & Aggr. buyer welfare & $\begin{array}{l}-3.4 \% \\
(1.0 \%)\end{array}$ & $\begin{array}{l}-6.4 \% \\
(1.5 \%)\end{array}$ & $\begin{array}{l}-1.7 \% \\
(33.3 \%)\end{array}$ \\
\hline & Platform turnover & $\begin{array}{l}-1.3 \% \\
(1.2 \%)\end{array}$ & $\begin{array}{l}-1.4 \% \\
(1.5 \%)\end{array}$ & $\begin{array}{l}-4.4 \% \\
(19.7 \%)\end{array}$ \\
\hline
\end{tabular}

Table 8: Changes in case non-price information gets concealed from the bidders. For all jobstartprice categories considered, the table displays the changes in the mean bidamount, the frequency with which the outside option is chosen, the aggregate welfare of the buyers, and the platform turnover in case nonprice information gets concealed. All auctions were conducted during the second half of 2008. Bootstrapped standard errors are given in parentheses. 


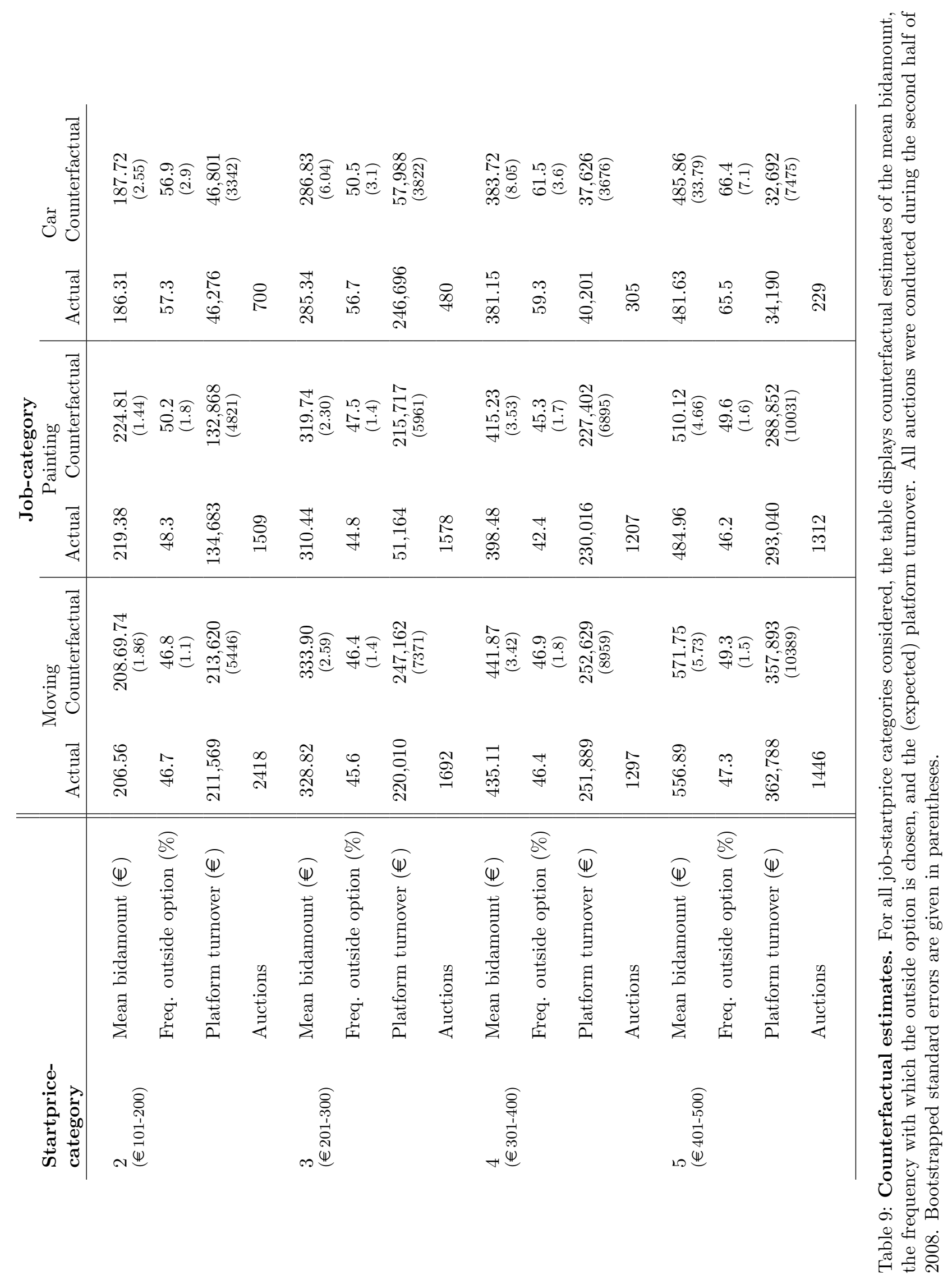

